\title{
Seasonal predictability of winter ENSO types in operational dynamical model predictions
}

\author{
Hong-Li Ren ${ }^{1,2}$ (i) - Adam A. Scaife, ${ }^{3,4}$ Nick Dunstone ${ }^{3} \cdot$ Ben Tian $^{1} \cdot$ Ying Liu $^{1} \cdot$ Sarah Ineson $^{3}$. June-Yi Lee ${ }^{5}$. \\ Doug Smith ${ }^{3} \cdot$ Changzheng Liu ${ }^{1} \cdot$ Vikki Thompson $^{3} \cdot$ Michael Vellinga $^{3} \cdot$ Craig MacLachlan $^{3}$
}

Received: 2 February 2018 / Accepted: 11 July 2018 / Published online: 25 July 2018

(c) The Author(s) 2018

\begin{abstract}
The El Niño-Southern Oscillation (ENSO) events of recent decades have been divided into the two different types based on their spatial patterns, the Eastern Pacific (EP) type and Central Pacific (CP) type. Their most significant difference is the distinguished zonal center locations of sea surface temperature (SST) anomalies in the equatorial Pacific. In this study, based on six operational climate models, we evaluate predictability of the two types of ENSO events in winter to examine whether dynamical predictions can distinguish between the two spatial patterns at lead time of 1 month and tell us more than simply whether an event is on the way. We show that winter EP and CP El Niño and La Niña events can only be distinguished in a minority of these models at 1-month lead, and the EP type tends to has a more realistic zonal positions of SST pattern centers than the CP type. Compared to the SST patterns, the differences between the two types are less apparent in precipitation especially for the two La Niña types in the models. Examinations of the extratropical teleconnections to the two ENSO types show that some of the models can reproduce the differences between EP and CP teleconnections. Evaluations of model predictions show that the EP El Niño event has the same level hit rate with the CP El Niño and the CP La Niña event has much higher hit rate than the EP La Niña. While the multi-model ensemble increases Niño index prediction skill, it does not help to improve forecast skill of center longitude index of the SST patterns and distinguish the two types of ENSO events. Although ENSO skill is very high at this lead time, the rapid loss of the initialized information on the different ENSO types in most of the models severely limits the predictability of the two types of winter ENSO events and more research is needed to improve the performance of climate models in forecasting the two ENSO types.
\end{abstract}

Keywords Two types of winter ENSO events $\cdot$ Predictability $\cdot$ Dynamical model $\cdot$ Evaluation

Hong-Li Ren

renhl@cma.gov.cn

1 Laboratory for Climate Studies and CMA-NJU Joint Laboratory for Climate Prediction Studies, National Climate Center, China Meteorological Administration, 46 Zhongguancun, Haidian District, Beijing 100081, China

2 Department of Atmospheric Science, School of Environmental Studies, China University of Geoscience, Wuhan 430074, China

3 Met Office Hadley Centre, Exeter, UK

4 College of Engineering, Mathematics and Physical Sciences, Exeter University, Exeter, UK

5 Research Center for Climate Sciences, Pusan National University, Busan, South Korea

\section{Introduction}

The El Niño Southern Oscillation (ENSO) phenomenon has been well known to play a key role in influencing global climate (e.g., Rasmusson and Carpenter 1982; Mason and Goddard 2001; Davey et al. 2014; Zhang et al. 1996). Now, the ENSO events in recent decades are often divided into two different types in terms of their spatial patterns. One is the canonical type of ENSO which has its sea surface temperature (SST) anomaly center over the equatorial Eastern Pacific (EP). The other one is a non-canonical type of ENSO, in additional to the canonical type, which has its major SST anomalies centered over the central Pacific (CP) regions. This non-canonical type is becoming more frequent since the late 1970s (Larkin and Harrison 2005a, b; Ashok et al. 2007; Kao and Yu 2009; Kug et al. 2009; Ren et al. 2013) and may become more frequent under a warming 
climate (Yeh et al. 2009). For this non-canonical type, there have been various nomenclatures and definitions in the literature, including the dateline El Niño (Larkin and Harrison 2005a, b), El Niño Modoki (Ashok et al. 2007), central Pacific ENSO (Kao and Yu 2009; Yeh et al. 2009; Yu et al. 2011), and WP El Niño/ENSO (Kug et al. 2009; Ren and Jin 2011, 2013). In this study, we will adopt the terminology of the EP and CP ENSO for describing the two types.

Many previous studies revealed that the CP type of El Niño has significantly different global climate impacts from the EP El Niño through tropical-extratropical teleconnections (e.g., Weng et al. 2007, 2009; Kim et al. 2009; Feng et al. 2010; Feng and Li 2011; Zhang et al. 2011, 2012; Yuan and Yang 2012) as these two types of El Niño are accompanied with distinct tropical atmospheric circulations. La Niña events, the negative phase of ENSO events, are usually less distinguishable in terms of the two types (Kug and Ham 2011). However, they were also divided into the two types in some studies (Ashok and Yamagata 2009; Yuan and Yan 2013), particularly if the decadal background is eliminated since 1980 (Ren et al. 2013). Indeed, the value of distinguishing the two types for either El Niño or La Niña events is clearest from their distinct global and regional climate impacts rather than their different SST patterns (Zhang et al. 2015). From this point of view, both types of El Niño and La Niña events will be focused on in this study.

Due to the significant impacts of ENSO on global climate, in recent 30 years, many international efforts were made towards ENSO prediction, and progress were made in improving skill levels of ENSO prediction (Latif et al. 1998; Jin et al. 2008; Barnston et al. 2012). A great many approaches were developed to predict ENSO, including statistical models, simplified air-sea coupled models, and fully coupled global climate models (GCMs) (e.g., Cane et al. 1986; Zebiak and Cane 1987; Chen et al. 1995, 2004; Kang and Kug 2000; Kirtman 2003; Luo et al. 2005, 2008; Zheng et al. 2006; Ham et al. 2009; Cheng et al. 2010; Izumo et al. 2010; Zhu et al. 2012, 2017; Ren et al. 2014; Liu and Ren 2017). Dynamical prediction based on fully coupled ocean-atmosphere GCMs has become a powerful tool for ENSO prediction as a result of large improvements in understanding ENSO, climate modeling, and ocean data assimilation. Here we test whether predicting the two ENSO types using the dynamical coupled GCMs is now possible given that they have already been shown to predict the canonical ENSO.

Previous studies have shown that most current coupled GCMs still have difficulty in reproducing the distinct SST anomaly patterns of two ENSO types due to model biases and other deficiencies (Yu and Kim 2010; Ham and Kug 2012). This presents a challenge to the dynamical prediction of the two ENSO types based on current GCMs. In comparison with the studies on prediction of the canonical ENSO, relatively little effort has been made to assess skill of the dynamical models in predicting the two types. In recent years, a few studies have used initialized hindcasts of some operational GCMs to do this. Hendon et al. (2009) and Lim et al. (2009) first attempted to predict differences between autumn modoki and canonical El Niños in the POAMA coupled seasonal forecast model of Australian Bureau of Meteorology (BoM) but the predictive lead time is limited to less than one season. Along this line, Jeong et al. (2012) found the lead time could be extended to 4 months for winter in the multi-model ensemble (MME) mean sense utilizing the hindcast data of the MME suite in the Asia-Pacific Economic Cooperation Climate Center (APCC), and Jeong et al. (2015) showed the predictability was subject to an apparent inter-decadal change. Yang and Jiang (2014) further showed the seasonal dependence of prediction skill of the two ENSO types for related SST anomalies and climate impacts in the Climate Forecast System version 2 (CFSv2) of National Centers for Environmental Prediction (NCEP). Zhu et al. (2015) examined prediction skill of the two types in the ECMWF prediction systems and found that the EP ENSO has higher skill than the CP. It has also been suggested that $\mathrm{CP}$ events may be more difficult to predict due to their smaller amplitude (Imada et al. 2015) and hence smaller signal to noise ratio. These studies overall indicate better performance for the EP ENSO than CP ENSO predictions though they are to some degree dependent on the principal components of tropical Pacific SST anomalies and the associated indices based on empirical orthogonal functions (EOFs) analysis, which are also unable to discriminate the asymmetry between El Niño and La Niña.

In this study, we will further examine the model predictability of these two types of ENSO by directly focusing on the El Niño and La Niña events that are well defined in the literature, based on initialized hindcasts from a group of current operational seasonal forecast systems. We aim to carry out a comprehensive event-based ENSO prediction evaluation and reveal whether dynamical predictions can distinguish the spatial differences between the two types of events and their teleconnections at seasonal lead times. This paper is organized as follows. Data and method are described in Sect. 2 . Comparisons of prediction skill and patterns of SST anomalies, precipitation responses, and teleconnections are given in Sects. 3, 4, and 5, respectively. We show event-based skill of predictions of different ENSO types in Sect. 6 and attempts using the MME method in Sect. 7. Summary and discussion are given in Sect. 8. 


\section{Data and method}

\subsection{Hindcast datasets from six operational seasonal forecast systems}

In this study, we use hindcast data of wintertime (December-January-February, DJF) initialized in November, collected from six operational prediction systems referred to as CFSv2, BCCv2, P24A, ECMWF4, G5GC2, and DPS3, respectively, and defined below. All of the models are fully coupled climate models that provide real-time operational predictions accompanying with hindcast datasets to evaluate and then calibrate these models.

CFSv2 is the Climate Forecast System version 2 from the NCEP, which is the upgraded version of CFSv1 (Saha et al. 2006) and has been used in operation since 2011. In CFSv2, there are substantial changes made from CFSv1, showing some significant advances in operational predictions (Saha et al. 2014). CFSv2 hindcast is a set of 9-month reforecasts initialized from every fifth day with four times of that day as totally 24 ensemble members, spanning the period of 1982-2010. To elongate the dataset, the real-time forecasts of 2011 are added. Initial conditions for the atmospheric and oceanic models are from the NCEP CFS Reanalysis (Saha et al. 2010).

$\mathrm{BCCv} 2$ is the second generation of climate forecasting system in Beijing Climate Center of China Meteorological Administration (BCC/CMA), a operational system from 2016. BCCv2 is based on the BCC Climate System Model version $1.1 \mathrm{~m}$ (BCC_CSM1.1 m) (Wu et al. 2013). Its atmospheric component is the BCC AGCM2.2 with a T106 horizontal resolution and 26 vertical levels (Wu et al. 2010), and its land component is the BCC Atmosphere and Vegetation Interaction Model version 1.0. The ocean component of BCCv2 is the Geophysical Fluid Dynamics Laboratory Modular Ocean Model version 4 and the sea ice component is the Sea Ice Simulator. BCCv2 hindcast is initiated from the 1st day of each month during 1991-2014 with a 13-mon integration. The atmospheric initial values are initialized from the four-time daily NCEP Reanalysis I and the oceanic initial values from variables of the NCEP Global Oceanic Data Assimilation System, using a nudging scheme of 3-D atmospheric fields and ocean temperature. Each hindcast includes 24 ensemble members by combining different atmospheric and oceanic initial conditions.

$\mathrm{P} 24 \mathrm{~A}$ is the operational seasonal prediction model in BoM (P24A) including BAMv3.0d (T47L17) and ACOM2 $\left(0.5^{\circ}-1.5^{\circ}\right.$ lat $\times 2^{\circ}$ lon L25) (Lim et al. 2012), participating in the Asia-Pacific Economic Cooperation Climate Center/ Climate Prediction and its Application to Society (APCC/ CliPAS) (Wang et al. 2009; Lee et al. 2010). POAMA stands for Predictive Ocean Atmosphere Model for Australia. POAMA is the Bureau of Meteorology's dynamical (physics based) climate model used for multi-week to seasonal through to inter-annual climate outlooks. It is a state of the art long-range forecast system using ocean, atmosphere, ice, and land data observations to initiate outlooks up to 9 months ahead. The P24A hindcast we use here is initialized on the 1st day of every month from 1981 to 2010, 30 years in total.

ECMWF4 is the European Centre for Medium-Range Weather Forecasts (ECMWF) System 4. ECMWF4 utilizes the ECMWF atmosphere model, with a higher resolution and a higher atmosphere top, and more ensemble members than the previous system (Molteni et al. 2011). The ECMWF4 hindcast is a set of 7-month seasonal reforecasts including 15 member ensembles, initialized on the 1st day of every month during 1981-2010, 30 years in total. More details of this system can be referred to http://www.ecmwf .int/products/forecasts/seasonal/documentation/system4.

G5GC2 is the Met Office global seasonal forecast system 5 (GloSea5) (MacLachlan et al. 2015). Its hindcasts used here were run in research mode over 1992-2011, using a 24 member ensemble. DPS3 is the Met Office decadal climate prediction system 3 (DePreSys3) (Dunstone et al. 2016). The DPS3 hindcasts used in this paper cover the period 1981-2014. DPS3 and G5GC2 use the same climate model but differ in the way in which they are initialized. G5GC2 is initialized directly from atmospheric fields of ECMWF ERA-Interim reanalysis data and its forced hindcast ocean reanalysis (GloSea5 Ocean and Sea Ice Analysis) that are coupled together on the first forecast time step (see MacLachlan et al. 2015 for details). Whereas DPS3 is via weakly coupled data assimilation, where analyzed monthly ocean temperature, salinity, and sea-ice concentration and reanalysis winds and temperatures are continuously nudged into the coupled model (see Smith et al. 2007; Knight et al. 2014, and Dunstone et al. 2016 for details). Forecasts are then branched off this assimilation run. In both G5GC2 and DPS3 the underpinning climate model is the Met Office global coupled model 2.0 (GC2). In this configuration the vertical resolution is 85 levels in the atmosphere (with a top at $85 \mathrm{~km}$ ) and 75 levels in the ocean (with a $1 \mathrm{~m}$ top level). The ocean horizontal resolution is $0.25^{\circ}$ on a tri-polar grid and in the atmosphere a horizontal resolution of $\mathrm{N} 216(60 \mathrm{~km}$ in mid-latitudes) is used. This model has been shown to have good representation of the modes of climate variability, including ENSO (Williams et al. 2015). Both G5GC2 and DPS3 use random seeds to drive a stochastic physics scheme in order to generate forecast ensemble members. We put the brief description of all the models into Table 1.

Anomalies of all hindcast variables are obtained by removing their own climate mean of the whole period of hindcast data used here. Winter means are used 
Table 1 Description of the six models

\begin{tabular}{|c|c|c|c|c|c|}
\hline System short names & Institutes (model names) & AGCM (resolution) & OGCM (resolution) & $\begin{array}{l}\text { Ensem- } \\
\text { ble } \\
\text { number }\end{array}$ & Data periods \\
\hline CFSv2 & NCEP (NCEP CFSv2) & GFS (T126L64) & MOM4 (1/4 Eq. L40) & 24 & 1982-2011 \\
\hline $\mathrm{BCCv} 2$ & BCC (BCC_CSM1.1 m) & BCC_AGCM2.2 (T106L26) & MOM4 $\left(1 / 3^{\circ}-1^{\circ}\right.$ lat $\times 1^{\circ}$ lon L40) & 24 & 1991-2014 \\
\hline $\mathrm{P} 24 \mathrm{~A}$ & BoM (POAMA) & BAMv3.0d (T47L17) & ACOM2 $\left(0.5^{\circ}-1.5^{\circ}\right.$ lat $\times 2^{\circ}$ lon L25) & 10 & $1981-2010$ \\
\hline ECMWF4 & ECMWF (ECMWF System4) & IFS cycle 36r4 (T255L91) & $\operatorname{NEMO}\left(1 / 3^{\circ}-1^{\circ} \mathrm{L} 42\right)$ & 15 & $1981-2010$ \\
\hline G5GC2 & Met Office (HadGEM3-GC2) & MetUM-GA3(N216L85) & NEMO-GO3 $\left(0.25^{\circ} \mathrm{L} 75\right)$ & 24 & 1992-2011 \\
\hline DPS3 & Met Office (HadGEM3-GC2) & MetUM-GA3(N216L85) & NEMO-GO3 $\left(0.25^{\circ} \mathrm{L} 75\right)$ & 40 & 1981-2014 \\
\hline
\end{tabular}

throughout the paper and constructed by averaging data for December-January-February (DJF).

\subsection{Observational reanalyses}

In this study, to verify the model hindcasts, we use the following observations: for SST we use HadISST (Rayner et al. 2003), for mean sea level pressure (MSLP) we use HadSLP2 (Allan and Ansell 2006), and for precipitation we use the Global Precipitation Climatology Project (GPCP) version 2.2 (Adler et al. 2003). Although the GPCP is limited to the satellite era (1979-onwards), it provides global coverage over the oceans which gaugebased datasets cannot provide. Observational anomalies in this paper are calculated from the climatology defined by the data during the period of 1981-2010.

Traditional Niño3.4, Niño3 and Niño4 indices of SST anomalies are used, which are defined as SST anomaly averages over the Niño3.4 region $\left(5^{\circ} \mathrm{S}-5^{\circ} \mathrm{N}, 170^{\circ}-120^{\circ} \mathrm{W}\right)$, Niño3 region $\left(5^{\circ} \mathrm{S}-5^{\circ} \mathrm{N}, 150^{\circ}-90^{\circ} \mathrm{W}\right)$, and Niño4 region $\left(5^{\circ} \mathrm{S}-5^{\circ} \mathrm{N}, 160^{\circ} \mathrm{E}-150^{\circ} \mathrm{W}\right)$, respectively. To quantify the two types of ENSO, we choose the Niño Warm-Pool index (denoted as WPI) and Niño Cold-Tongue index (denoted as CTI) that were proposed by Ren and Jin (2011) for representing the CP and EP ENSO types, respectively, based on a nonlinear transformation of Niño3 and Niño4 indices; i.e., WPI $=$ Niño $4-\alpha$ Niño3 and CTI $=$ Niño3 $-\alpha$ Niño4, where $\alpha=0.4$ when Niño $3 *$ Niño4 $>0$; otherwise, $\alpha=0$.

\subsection{Evaluation methods}

In this study, we carry out an evaluation through the eventbased method. That is, we focus on the patterns of the two ENSO types based on composites of historical events. To define the El Niño or La Niña events, we refer to the definition of Yeh et al. (2009), namely contrasting differences between Niño3 and Niño4 indices either exceeding $0.5^{\circ} \mathrm{C}$. We identify historical events which are mainly consistent with the literature (e.g., Kao and Yu 2009; Kim et al. 2009; Kug et al. 2009; McPhaden et al. 2011; Xiang et al. 2013) that has been well recognized. Note that the classification for La Niña events is still controversial. Here we directly refer to the previous study (Zhang et al. 2015). The winters for the different types of winter-mean ENSO indices are listed in Table 2.

Composite patterns for observation are calculated by averaging the anomalous fields that correspond to the different types of events. For the model hindcasts, composite patterns are calculated in terms of the observed events for the different types, where the predicted ENSO events can be identified using ensemble means of these models with the available data periods for the same years as in the observations. In this study, we remove the linear trend from all of the data before doing analyses.

\section{Comparisons of patterns of SST anomalies}

First of all, as a reference, Fig. 1 presents skill of ENSO prediction based on winter Niño indices in the models. It is clearly seen that Niño3.4 index has the highest skill score
Table 2 Events of two types of El Niño and La Niña from $1981 / 82$ to $2014 / 15$ winters

\begin{tabular}{llc}
\hline Types & Winters & Numbers \\
\hline EP El Niño & $1982 / 83,1986 / 87,1991 / 92,1997 / 98,2006 / 07$ & 5 \\
CP El Niño & $1987 / 88,1994 / 95,2002 / 03,2004 / 05,2009 / 10,2014 / 15$ & 6 \\
EP La Niña & $1984 / 85,1995 / 96,1999 / 00,2005 / 06,2007 / 08$ & 5 \\
CP La Niña & $1983 / 84,1988 / 89,1998 / 99,2000 / 01,2008 / 09,2010 / 11,2011 / 12$ & 7 \\
\hline
\end{tabular}




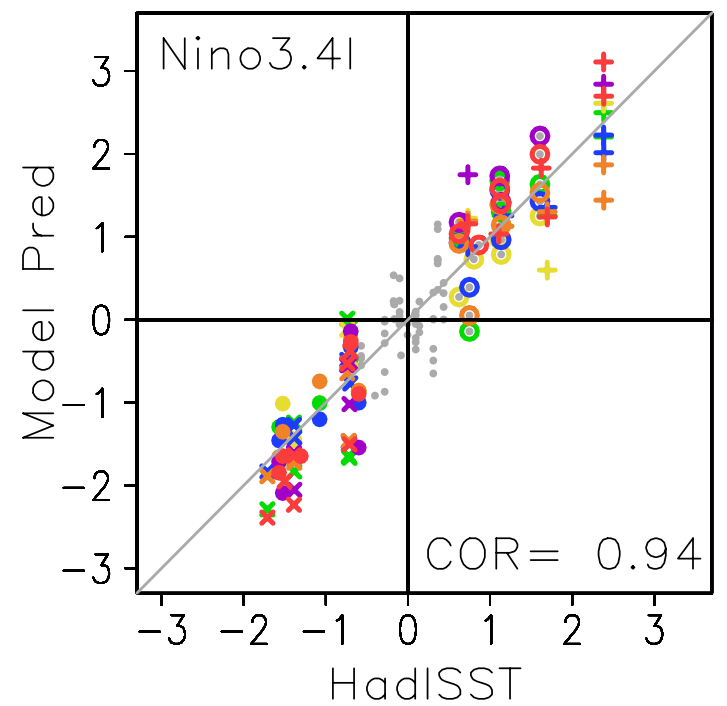

$\begin{array}{ll}+ & E P-E L \\ 0 & C P-E L \\ - & E P-L A \\ \times & C P-L A \\ - & \text { Neutral }\end{array}$

CFSV 2

P24A

ECMF 4

G5GC2

DPS3
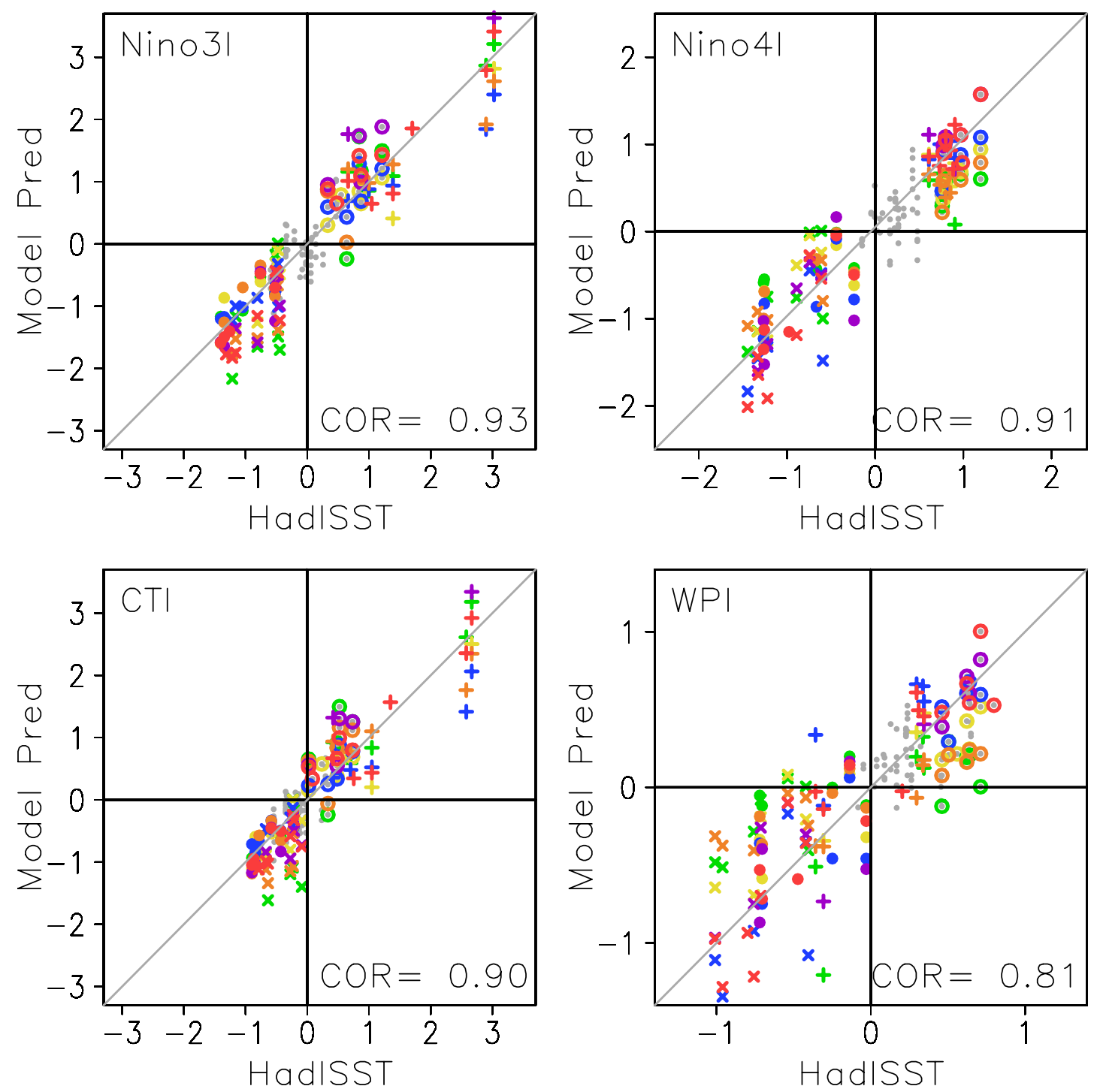

Fig. 1 Scatter maps of the HadISST (x-axis) and model predictions (y-axis) for DJF-mean Niño3.4 index, Niño3 index, Niño4 index, CTI, and WPI. Each symbol denotes one DJF mean. CORs are correlation coefficients for all of value pairs and colors are for different models 


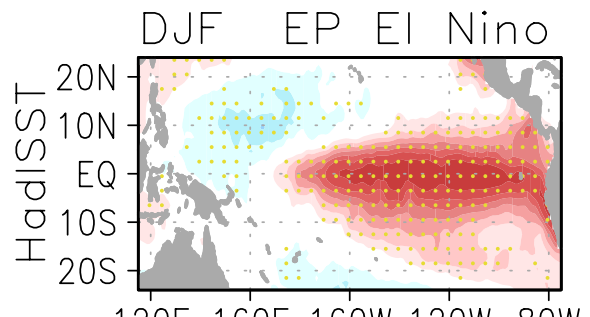

120E 160E 160W 120W 80W

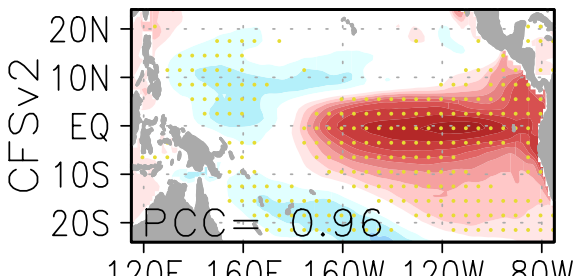

120E 160E 160W 120W 80W

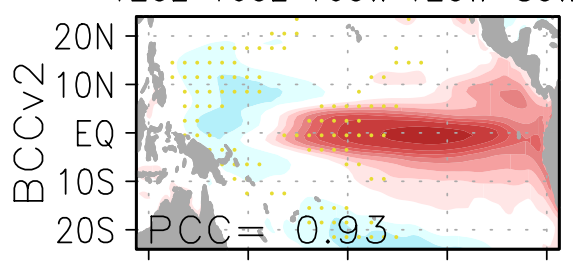

120E 160E 160W 120W 80W
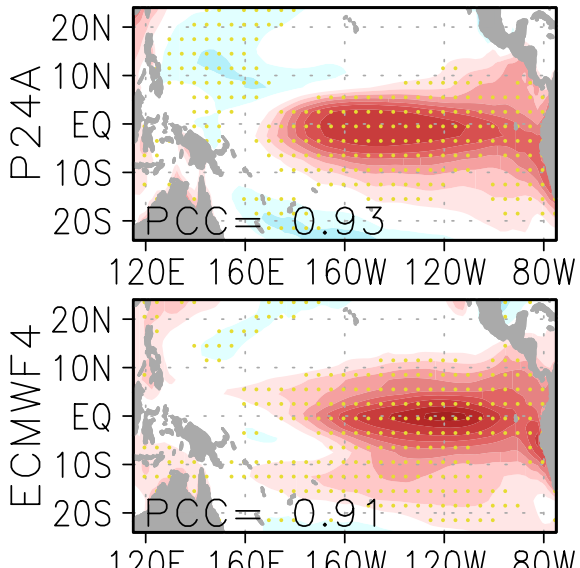

120E 160E 160W 120W 80W

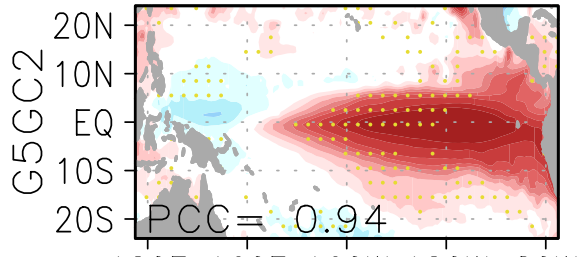

120E 160E 160W 120W 80W

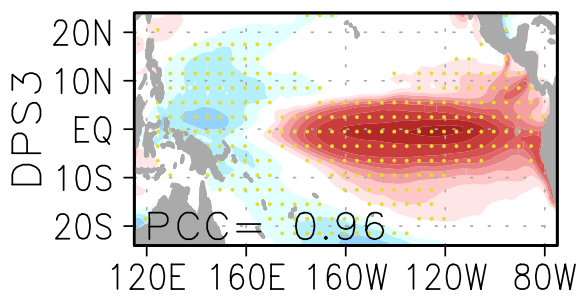

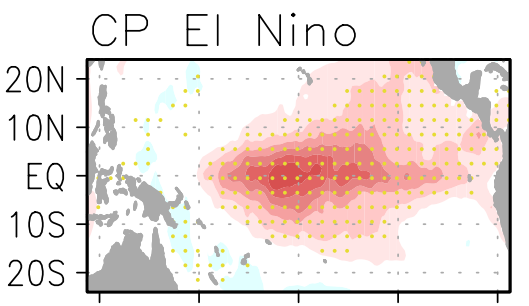

120E 160E 160W 120W 80W

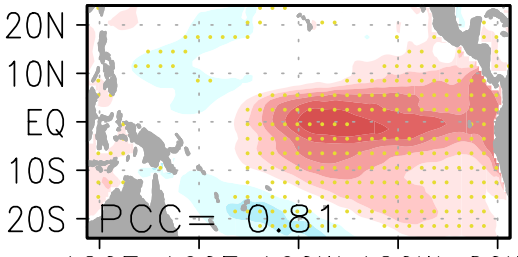

120E 160E 160W 120W 80W

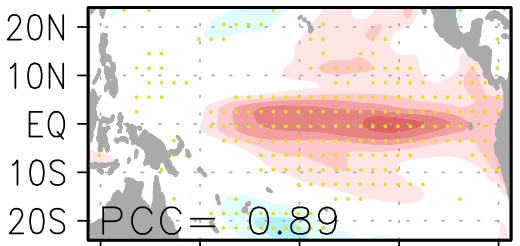

120E 160E 160W 120W 80W

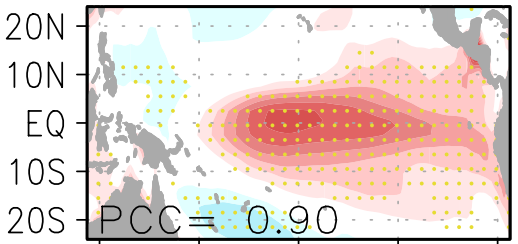

120E 160E 160W 120W 80W

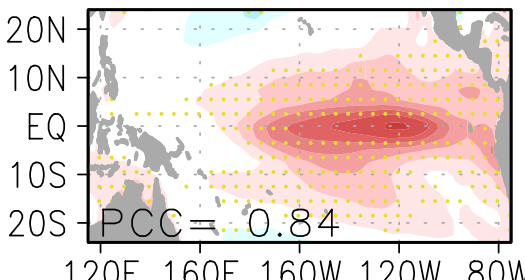

120E 160E 160W 120W 80W

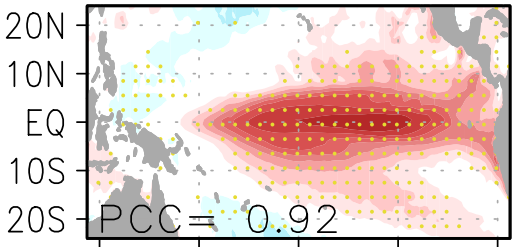

120E 160E 160W 120W 80W

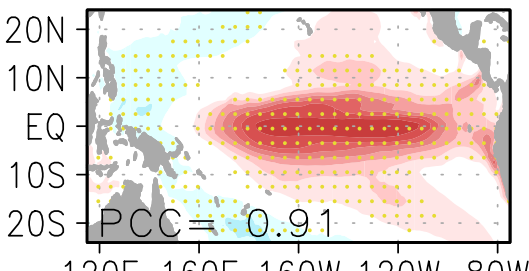

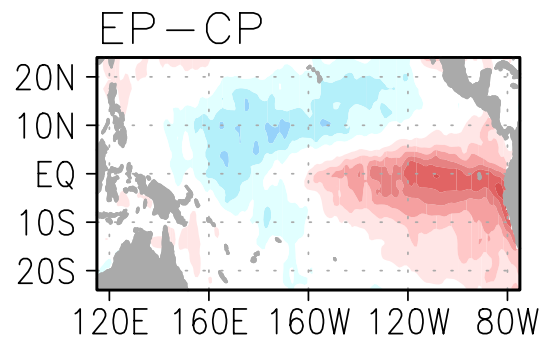

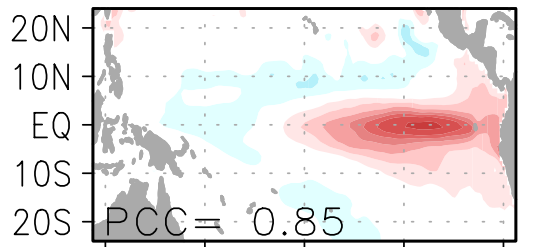

120E 160E 160W 120W 80W

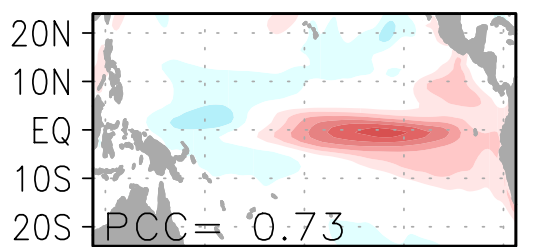

120E 160E 160W 120W 80W

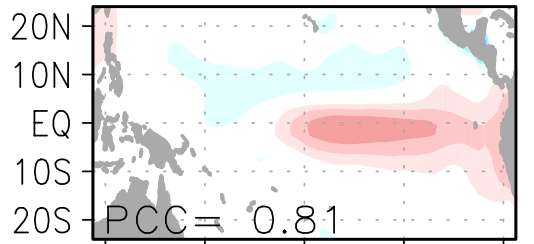

120E 160E 160W 120W 80W

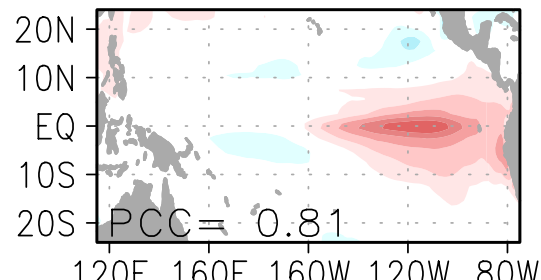

120E 160E 160W 120W 80W

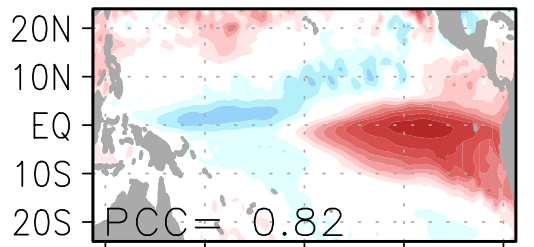

120E 160E 160W 120W 80W

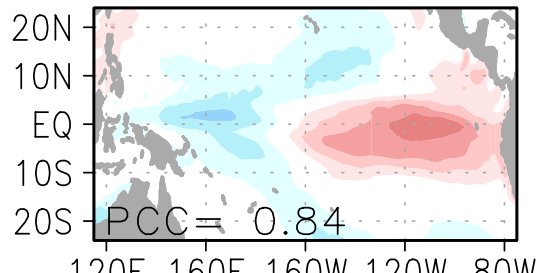

120E 160E 160W 120W 80W

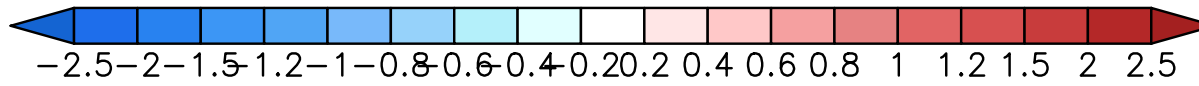


४Fig. 2 Composite patterns of SST anomalies (unit: ${ }^{\circ} \mathrm{C}$ ) for the EPtype (left panels) and CP-type (middle panels) El Niño events as well as their differences (right panels) based on the observation (top three panels) and model hindcasts (below panels). Black numbers in panels are pattern correlation coefficients (PCCs) between the model patterns and the corresponding observation pattern. Yellow dots denote the $t$-test significance at the $95 \%$ confidence level

with a correlation coefficient of 0.94 between observations and predictions at 1 month lead. All the model forecasts are highly consistent with the observed El Niño, Neutral, and La Niña phases, and a similar situation is found for the EP cases, with slightly reduced correlations of 0.93 and 0.90 for Niño3 index and CTI, respectively. As a comparison, the skill score in WPI for the CP type is relatively lower (correlation is 0.81) and the spread across models is clearly larger. Meanwhile, Niño4 index is also highly predictable (correlation is 0.91), which is sometimes used to represent the CP type. These results confirm previous studies in which the indices for representing the two types are usually well predicted, particularly within a few months lead. The composite spatial patterns of SST anomalies of the EP and CP El Niño events (Table 2) over the equatorial Pacific in observations and the six different models are shown in Fig. 2. A distinct difference between the EP and $\mathrm{CP}$ events is shown in the observations. The EP events are stronger, with the largest anomalies occurring between $160^{\circ} \mathrm{W}$ and the eastern boundary, and extending southwards along the Peruvian coastline. In contrast, the $\mathrm{CP}$ events show the centers of equatorial SST anomalies between 170 and $150^{\circ} \mathrm{W}$. The EP-CP difference plot shows the EP events have greater warming in the south-east but are generally cooler north of the equator and in the west.

All of the models assessed show stronger EP than CP events, agreeing well with the observations, where the pattern correlation coefficients (PCCs) are generally above 0.9 and 0.80 for the EP and CP types, respectively, as shown in Fig. 2. However, some do not show as much separation between the two types as several of the model composites for the CP type show maximum SST anomalies to the east of the observed maximum. In the models the CP events also tend to show overestimated warming along the Peruvian coast although we note that the modeled EP events remain stronger in this region. The differences between EP and $\mathrm{CP}$ events in the western Pacific are also generally poorly represented in the models, with several showing underestimated relative cooling, presumably due to the well-known westward extension bias of ENSO anomalies (e.g., Ham and Kug 2015). Among the models, DPS3 best represents the observed differences of the two ENSO types, CFSv2 also performs well but shifts $\mathrm{CP}$ events too far east, and G5GC2 overstates the differences with greater anomalies during EP events although this may be due to relatively smaller sample size of its hindcast still including the large 1997/98 event.
Figure 3 shows the La Niña composite SST anomalies. In observations the difference between the two event types is less distinct than that for El Niño events. The $\mathrm{CP}$ events are slightly stronger in the central Pacific, and weaker in the eastern equatorial Pacific, also showing a greater cooling anomaly than EP events in the southeast tropical Pacific. The difference between the EP and $\mathrm{CP}$ events is also less distinct in the models, compared to the two El Niño types. As seen in Fig. 3, although the PCCs are still above 0.9 and 0.80 for the two types, those for the EP-CP differences are all below 0.70. Meanwhile, although a majority of the models correctly show stronger CP La Niña events, two of the models, BCCv2 and G5GC2, do not. Two models, CFSv2 and DPS3, show the cooling anomaly extending into the southeast tropical Pacific in CP events, as seen in observations. As with the El Niño composites, several of the models have maximum anomalies in the $\mathrm{CP}$ events eastward of the observed position.

Generally, the models predict the differences between EP and CP events in El Niño better than in La Niña. The observations show smaller anomaly differences between the EP and CP La Nina events than in El Niño conditions. DPS3 best simulates the observed differences between the EP and CP events, though all models capture some of the characteristics. Figure 4 collectively contrasts the central positions of the SST anomaly patterns shown in Figs. 2 and 3 for the EP and $\mathrm{CP}$ event composites by directly identifying the center longitude index (CLI) that is defined as the center longitude where the amplitude of equatorial-mean $\left(5^{\circ} \mathrm{S}-5^{\circ} \mathrm{N}\right) \mathrm{SST}$ anomaly reaches maximum. In observations the SST centers of the CP ENSO types are steadily located west of $160^{\circ} \mathrm{W}$ and those of the EP types are east of $145^{\circ} \mathrm{W}$. The longitudinal separation of the two types of La Niña events is evidently less than that between the two types of El Niño events.

In Fig. 4, almost all of the models have relatively realistic longitudinal center positions for the EP type in both El Niño and La Niña conditions except that P24A shows a strong westward shift. However, for the CP type only DPS3 and P24A have positions close to those observed, with the other models showing a clear eastward displacement, where DPS3 does the best job. This conclusion would be much clearer in Fig. 5 when we extract the main longitudinal center positions of the two types. It is quite clearly seen in Fig. 5 that the canonical center longitudes of EP and CP El Niño events can only be distinguished by $2-3$ models, and this is slightly less true for La Niña events where four out of six models are unable to distinguish the canonical center positions between the two types of La Niña events. 


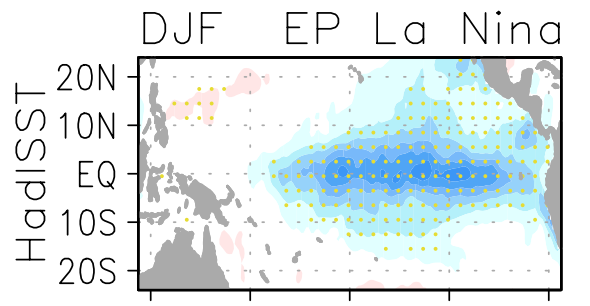

120E 160E 160W 120W 80W

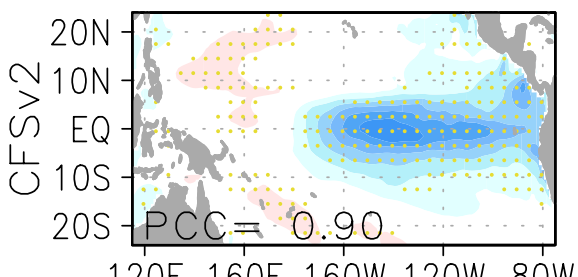

120E 160E 160W 120W 80W

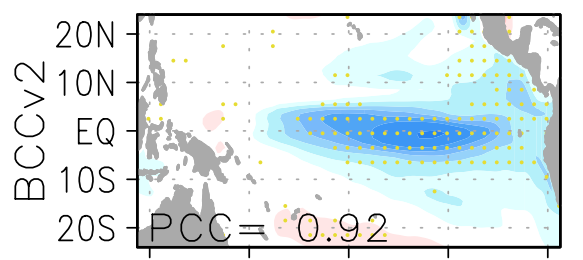

120E 160E 160W 120W 80W
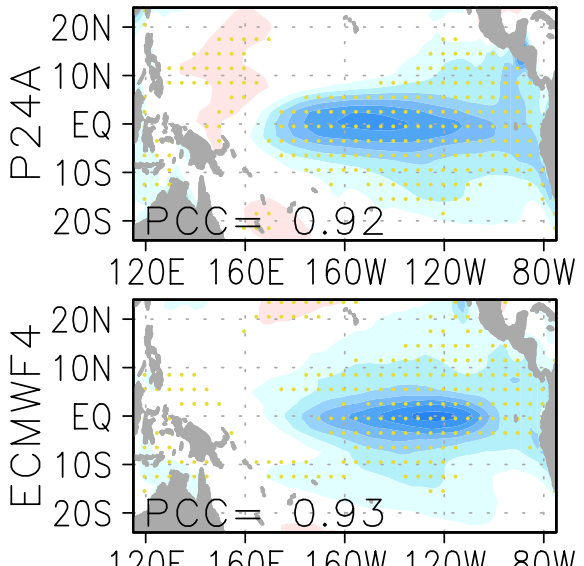

120E 160E 160W 120W 80W

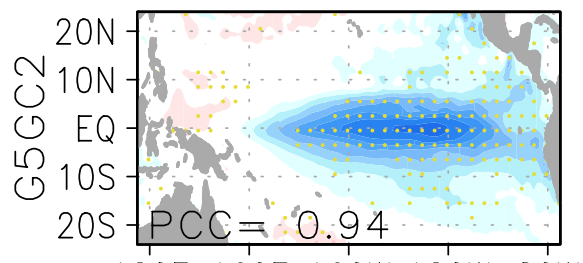

120E 160E 160W 120W 80W

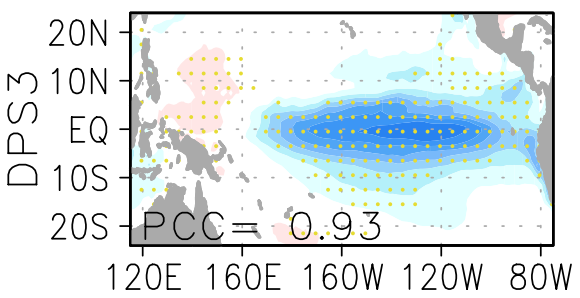

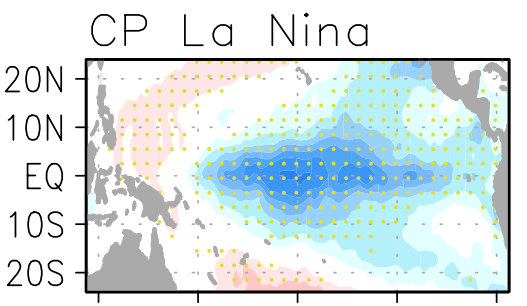

120E 160E 160W 120W 80W

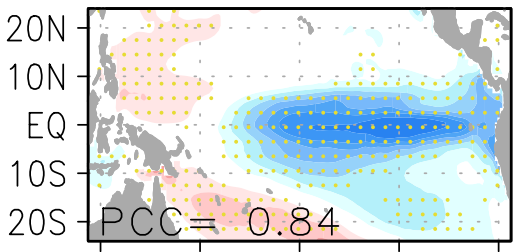

120E 160E 160W 120W 80W

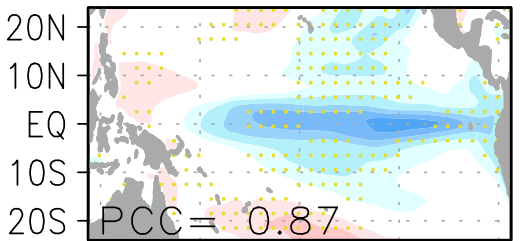

120E 160E 160W 120W 80W

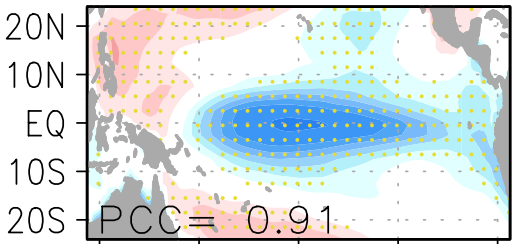

120E 160E 160W 120W 80W

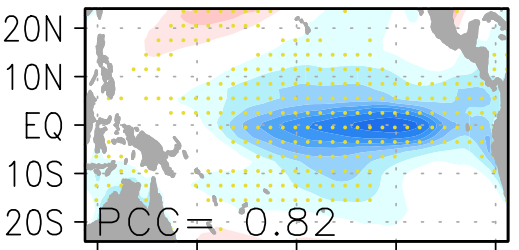

120E 160E 160W 120W 80W

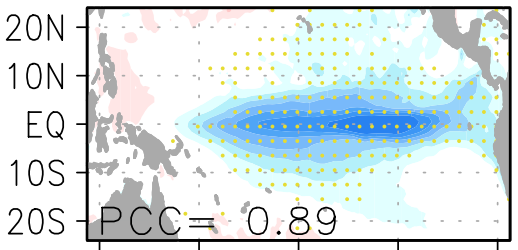

120E 160E 160W 120W 80W

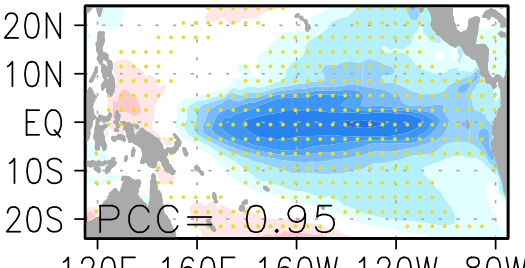

120E 160E 160W 120W 80W
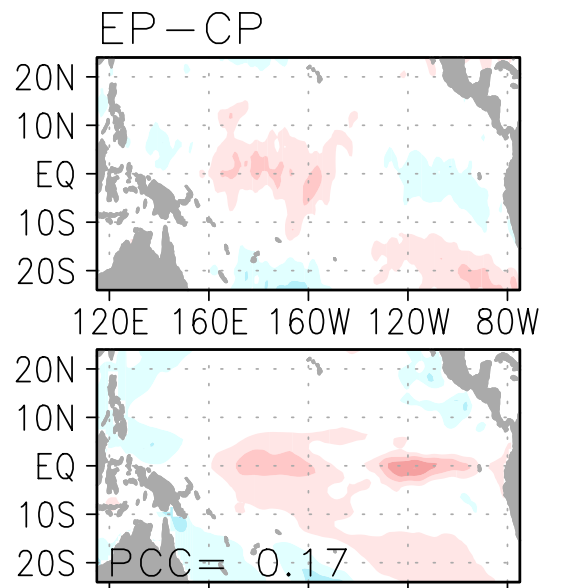

120E 160E 160W 120W 80W

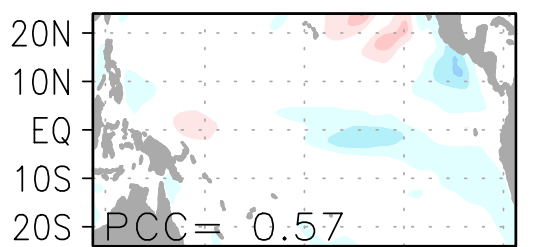

120E 160E 160W 120W 80W

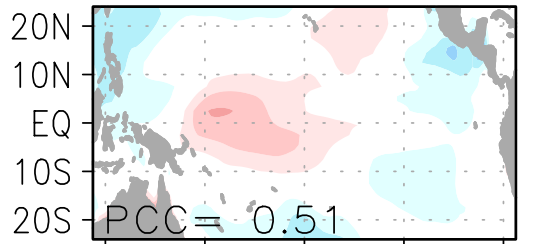

120E 160E 160W 120W 80W

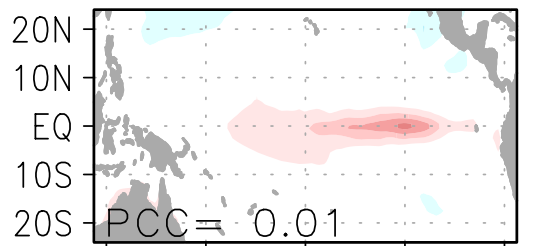

120E 160E 160W 120W 80W

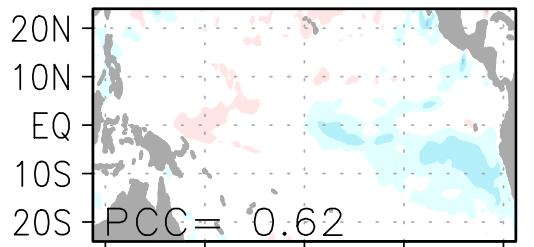

120E 160E 160W 120W 80W

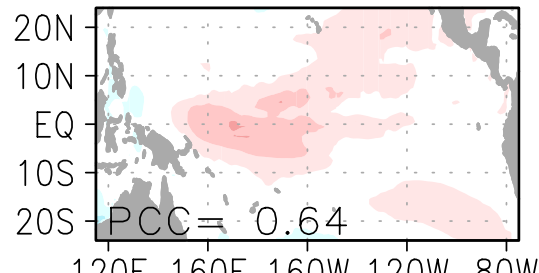

120E 160E 160W 120W 80W

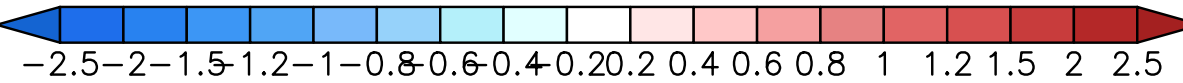

Fig. 3 The same to Fig. 2, but for the two types of La Niña events 
(a) EP El Nino

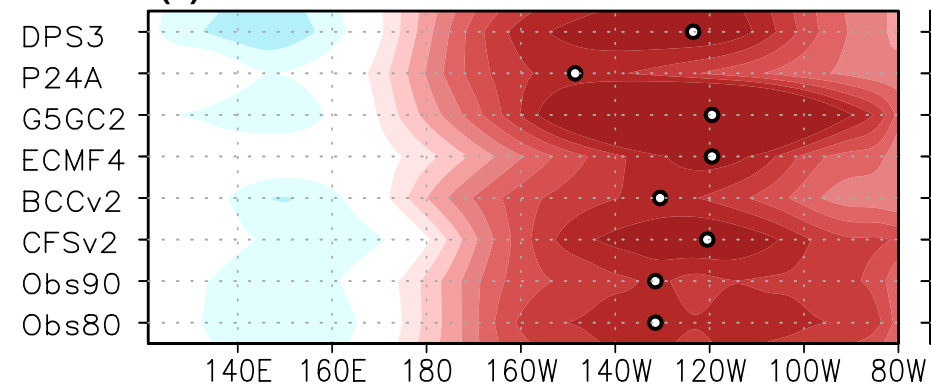

(c) CP El Nino (b) EP La Nina

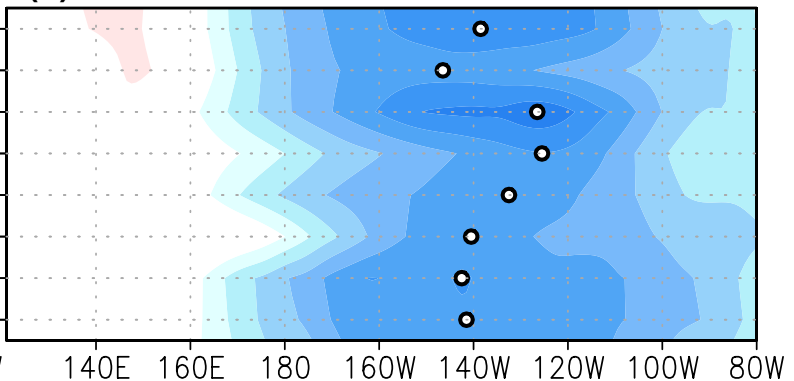

(d) CP La Nina

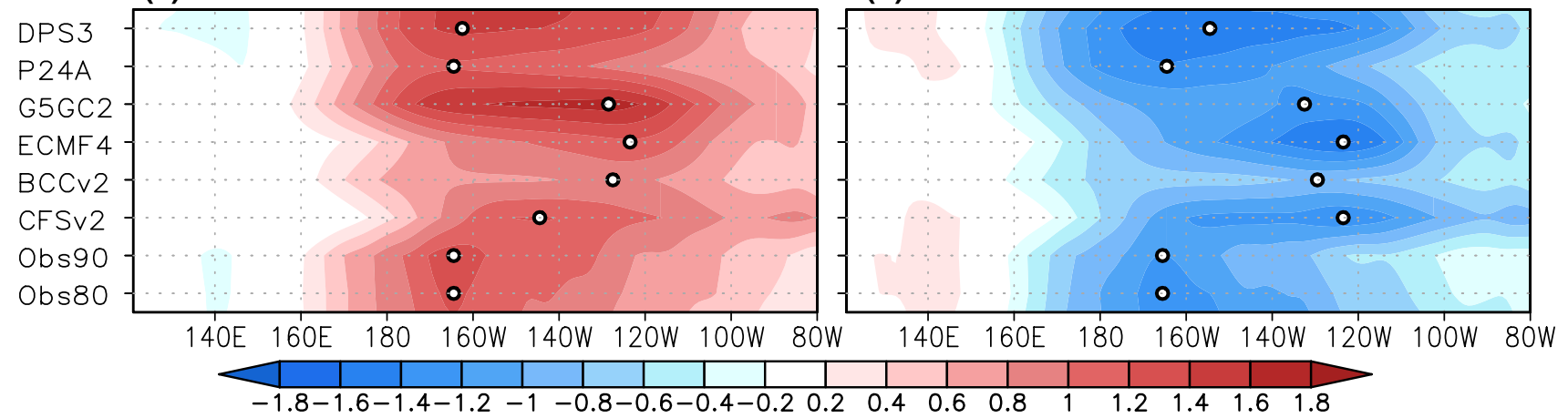

Fig. 4 Equatorial mean $\left(5^{\circ} \mathrm{S}-5^{\circ} \mathrm{N}\right)$ of SST composite patterns of observation and predictions for different ENSO types (a-d), where Obs80 and Obs90 denote the HadISST results of 1980-2014 and 1990-2014 periods, respectively
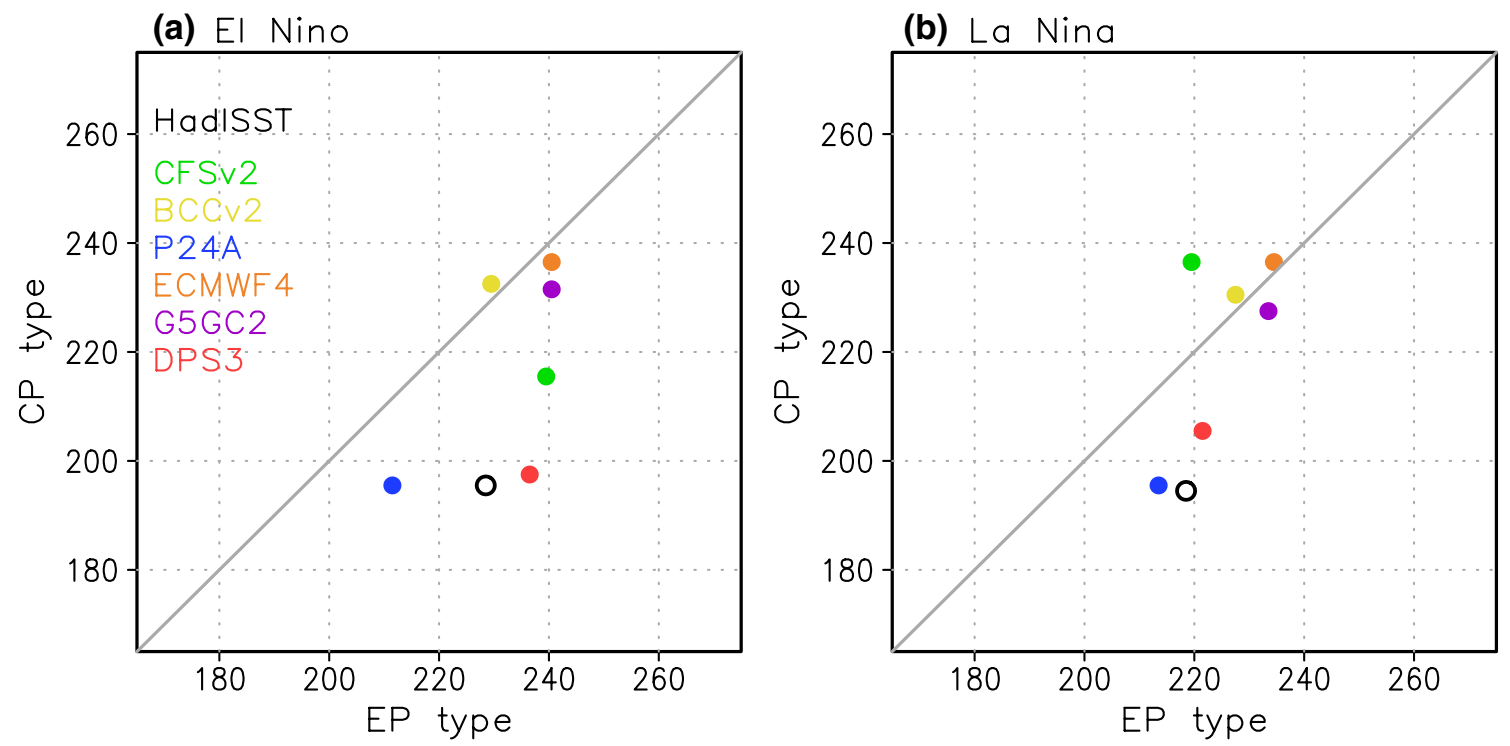

Fig. 5 Scatter maps between SST anomaly center longitudes (viz. LPIs shown in Fig. 4) of two types of El Niño (a) and La Niña (b). Colored dots denote the model results. Black circles are for the HadISST results during 1980-2014 period. Unit of the two axes is ${ }^{\circ} \mathrm{E}$

\section{Patterns of precipitation responses}

Figure 6 shows precipitation anomalies for the composites of EP and CP El Niño events for observations and model hindcasts. The observations show during EP events the precipitation is enhanced along the equatorial region from $160^{\circ} \mathrm{E}$ to $80^{\circ} \mathrm{W}$, with the SPCZ displaced to the north and east of its climatological position and the ITCZ, which lies to the north of the equator, displaced strongly southward, 

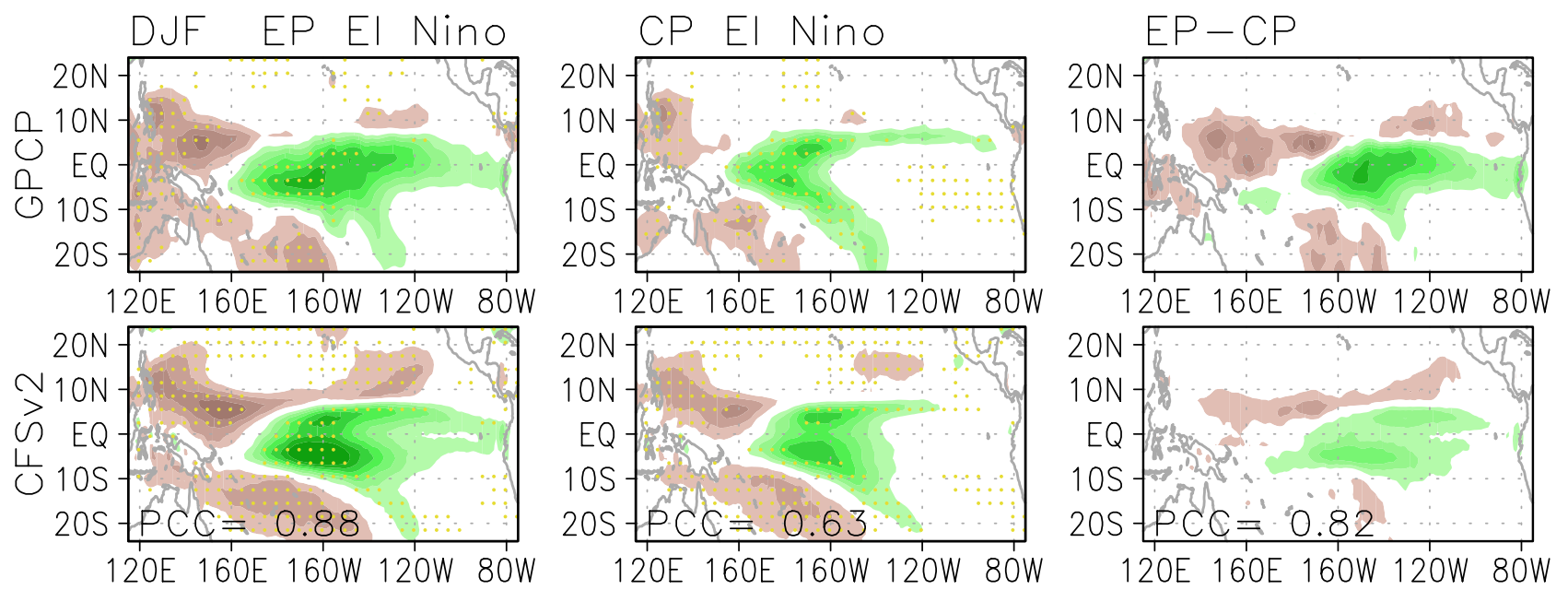

120E 160E 160W 120W 80W
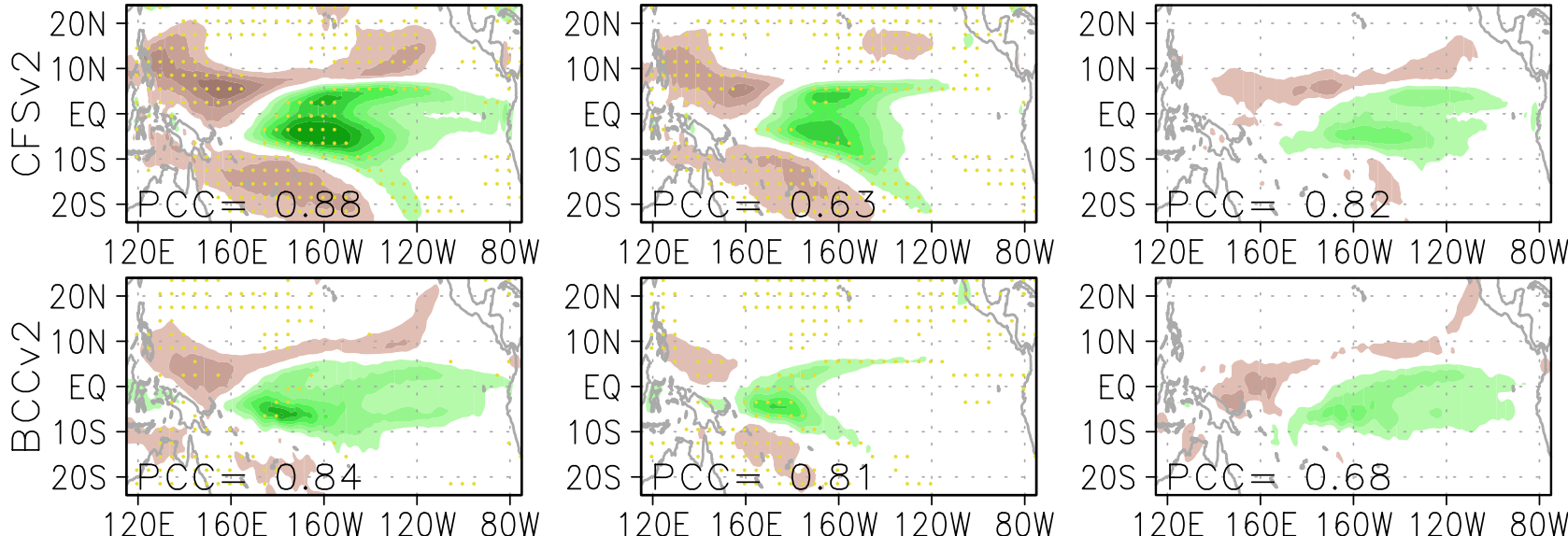

120E 160E 160W 120W 80W
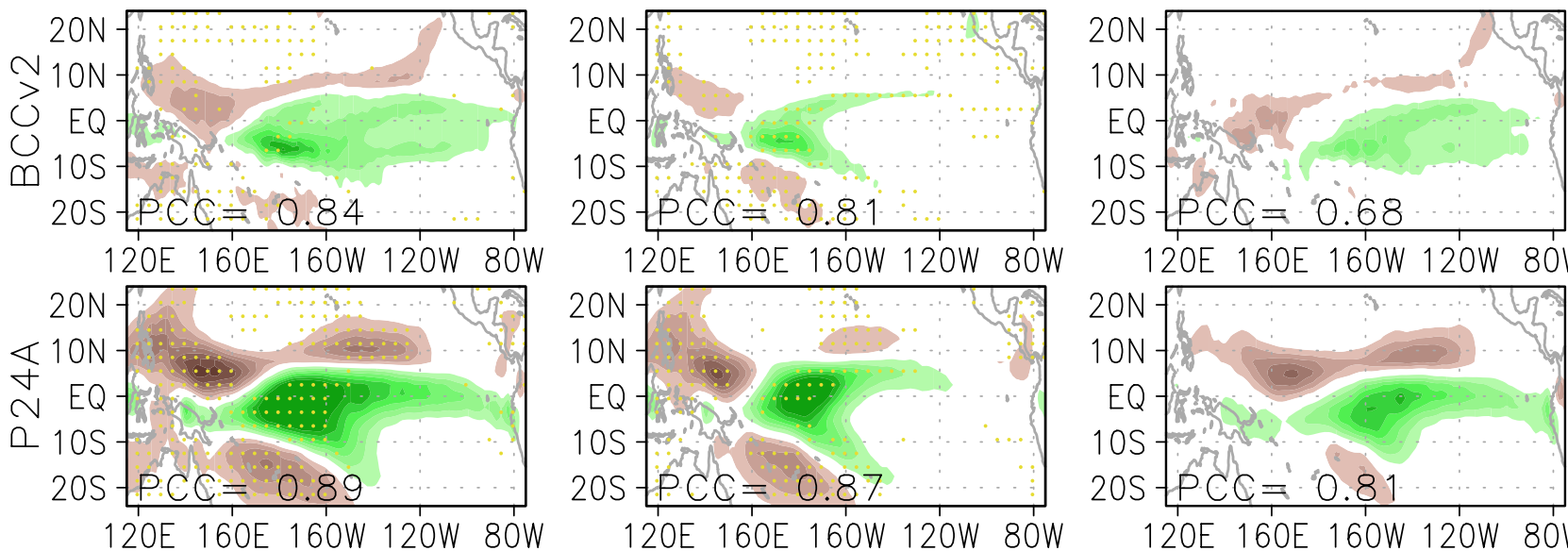

120E 160E 160W 120W 80W

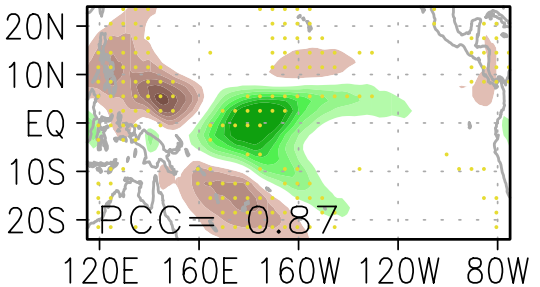

120E 160E 160W 120W 80W
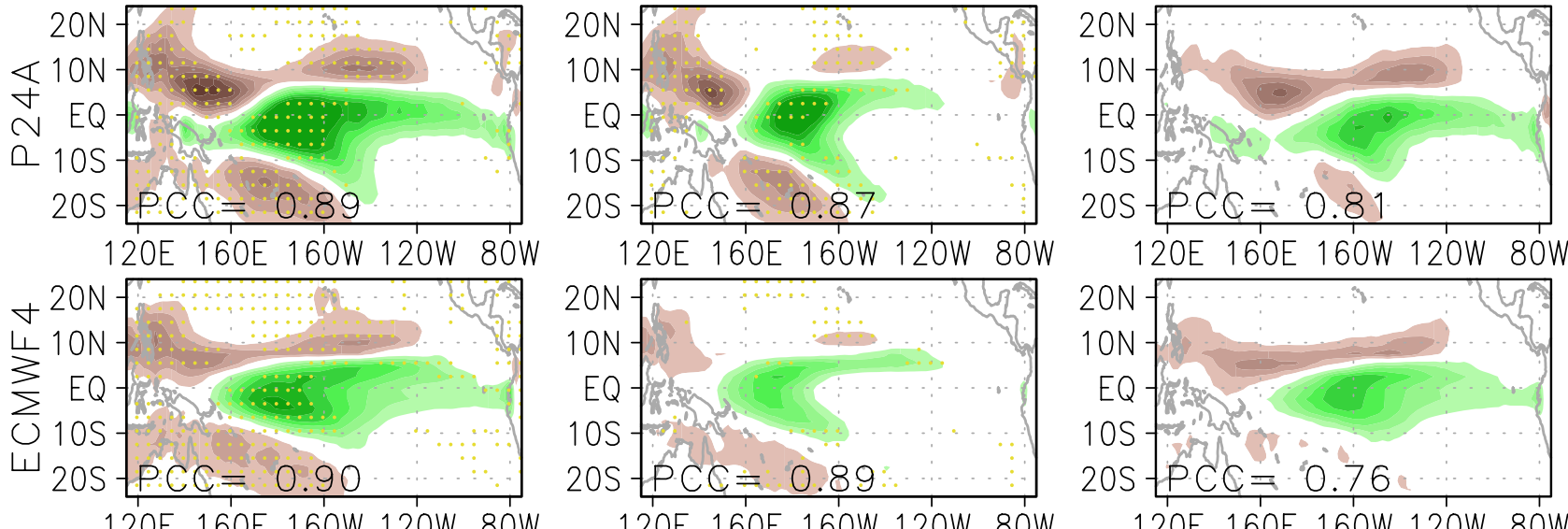

120E 160E 160W 120W 80W

120E 160E 160W 120W 80W

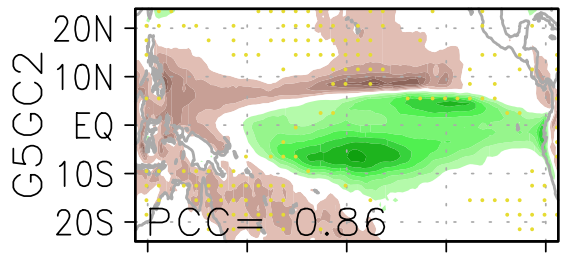

$10 \mathrm{~S}$

$20 S-P C C=0.89$
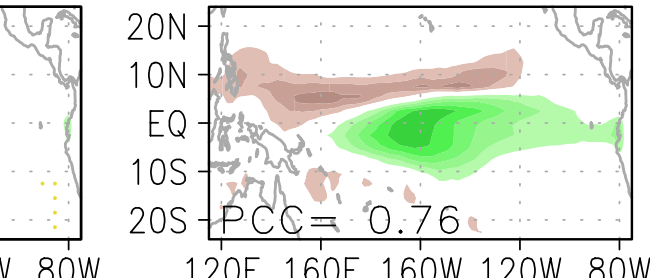

120E 160E 160W 120W 80W

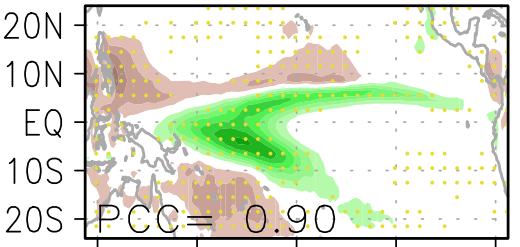

120E 160E 160W 120W 80W

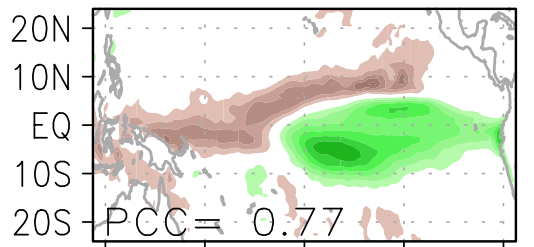

120E 160E 160W 120W 80W

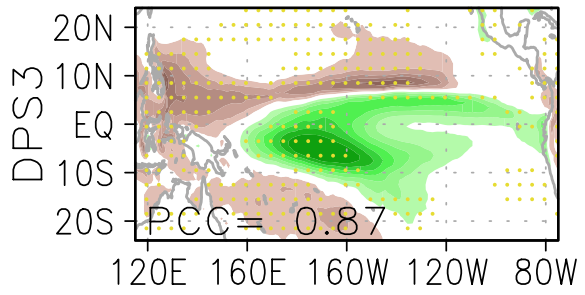

120E 160E 160W 120W 80W

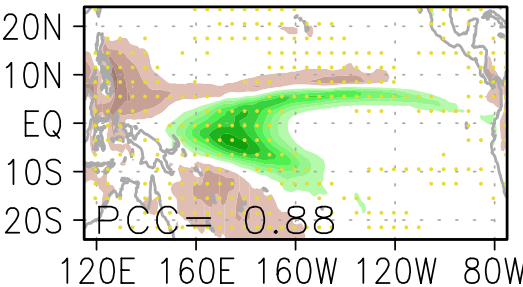

120E 160E 160W 120W 80W
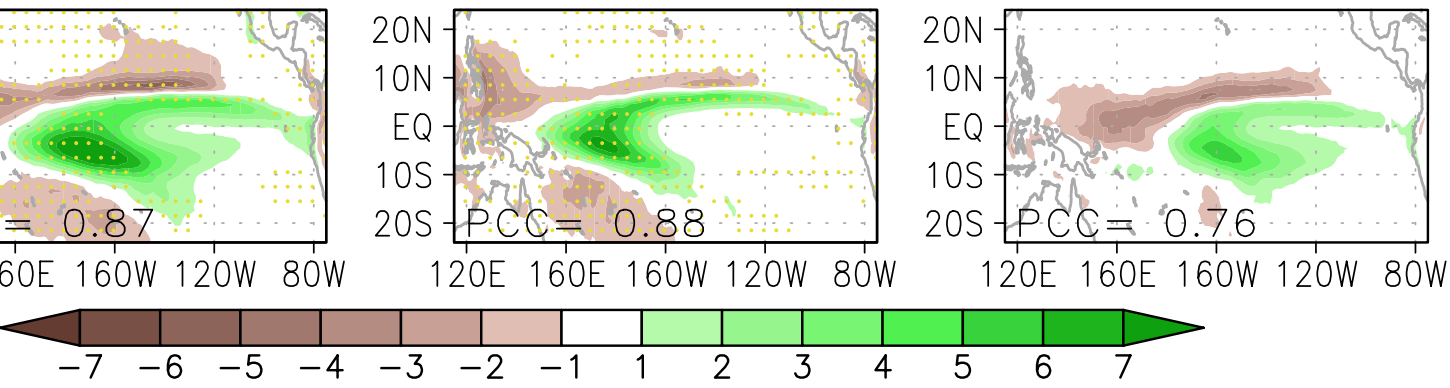
४Fig. 6 Composite patterns of precipitation anomalies (unit: $\mathrm{mm} /$ day) for the EP-type (left panels) and CP-type (middle panels) El Niño events as well as their differences (right panels) based on the observation (top three panels) and model hindcasts (below panels). Black numbers in panels are PCCs between the model patterns and the corresponding observation pattern. Yellow dots denote the $t$-test significance at the $95 \%$ confidence level

resulting in a largely zonal feature along the equator. Precipitation tends to be weaker than normal over northern Australia, maritime Southeast Asia, and the Philippines. The pattern during $\mathrm{CP}$ events has a quite different spatial structure. That is, enhanced precipitation largely occurs between $160^{\circ} \mathrm{E}$ and $160^{\circ} \mathrm{W}$, with anomalies of less than $1 \mathrm{~mm} /$ day to the east of $160^{\circ} \mathrm{W}$, and the SPCZ and ITCZ are distinct features with the SPCZ extending southwestwards from the equator and shifted less strongly to the east and the ITCZ displaced less strongly southward. This leads to a difference map showing stronger precipitation along the equatorial region in EP events, with weaker bands either side.

Many of the models show the rainfall differences between the EP and CP events well (Fig. 6, lower panels). The precipitation anomalies are generally greater in the models than seen in observations except BCCv2. The plots of the differences between EP and CP events show stronger equatorial precipitation anomalies in EP events with a band of weaker precipitation to the north. P24A most clearly shows less precipitation to the south in EP events although there are traces of this in other models. DPS3 is less successful at capturing the zonal nature of the EP pattern in the eastern Pacific than some other models, with the enhanced precipitation lying mainly to the north of the equator. This bias is also apparent, to a lesser extent in G5GC2 and CFSv2.

As was shown for SSTs, for La Niña conditions the difference between precipitation patterns of the $\mathrm{EP}$ and $\mathrm{CP}$ events is not as clear as for El Niño conditions. Figure 7 shows maps of the spatial precipitation patterns. The observations show very similar patterns in EP and CP events with negative precipitation anomalies around the equator and positive anomalies on the western coasts. The $\mathrm{CP}$ events show greater decreases of precipitation east of $150^{\circ} \mathrm{E}$. The intermodel spread is large in capturing the precipitation response to the two La Niña types. P24A shows larger anomalies than observed, but BCCv2 shows weaker anomalies. In DPS3 and G5GC2 the negative anomalies extend too far east north of the equator, and in $\mathrm{BCCv} 2$ the anomalies do not extend far enough east. Despite these differences in the anomaly patterns, the differences between the EP and CP events are similar between the models, showing a greater decrease in precipitation in the $\mathrm{CP}$ events in agreement with observations. Clearly, the models have a less capability of reproducing the difference between the two La Niña types than that between the two El Niño ones, as shown by the PCCs in the right panels of Figs. 6 and 7.

Further, Fig. 8 collectedly shows contrast of the center positions of the precipitation anomaly patterns shown in Figs. 6 and 7 for the EP and CP event composites by identifying their center longitude index (CLI), same as to that of the SST anomaly but with the equatorial-mean $\left(5^{\circ} \mathrm{S}-5^{\circ} \mathrm{N}\right)$ precipitation anomaly reaching its maximum. The observed rainfall centers of the CP El Niño types are steadily located west of around 180 and around east of $160^{\circ} \mathrm{W}$ for the EP types, whereas those of the EP and CP La Niña types are almost undistinguishable in terms of their longitudinal positions. The ability of the models to distinguish the canonical rainfall pattern centers between the two types is significantly lower than that in distinguishing the SST pattern centers.

\section{Patterns of teleconnections}

ENSO teleconnections provide a potential predictability source of extratropical climate prediction skill on seasonal (e.g., Jia et al. 2012; Jeong et al. 2012; Lee and Ha 2015; Scaife et al. 2017a) and perhaps longer interannual timescales. However, it is difficult from observational records to decide whether these influences are variable from one event to another (e.g., Greatbatch et al. 2004; Toniazzo and Scaife 2006), or simply the same in all events but masked in some cases by other climate variability so that long records are required to extract stable teleconnections (Brönnimann et al. 2007). Ensemble hindcasts used in this study provide the opportunity to decide between these two possibilities and potentially identify robust teleconnection patterns by using the ensembles to minimize unpredictable internal variability.

Figure 9 shows teleconnections to EP and CP El Niño events in observational analysis and a number of hindcast sets. All models successfully generate the Pacific teleconnection pattern during EP events with high pressure in the tropical west Pacific and low pressure over the Aleutians in North Pacific. Similar signatures to the observed pattern are also reproduced in the southern hemisphere with a sequence of high-low-high pressure features terminating off the tip of South America. Atlantic patterns are weaker but DPS3 and G5GC2 show high pressure close to northwest Europe in a pattern similar to that identified in the strongest El Niño events (Toniazzo and Scaife 2006) and which occurs when stratospheric polar vortex is undisturbed (Bell et al. 2009; Ineson and Scaife 2009).

In $\mathrm{CP}$ events the Pacific teleconnections are similar in pattern but weaker in amplitude, as expected given the generally lower amplitude of CP events (Fig. 2). However, the Atlantic response is much clearer in $\mathrm{CP}$ events with a negative NAO like response in the observational composite. This pattern dominates the overall Atlantic response to 

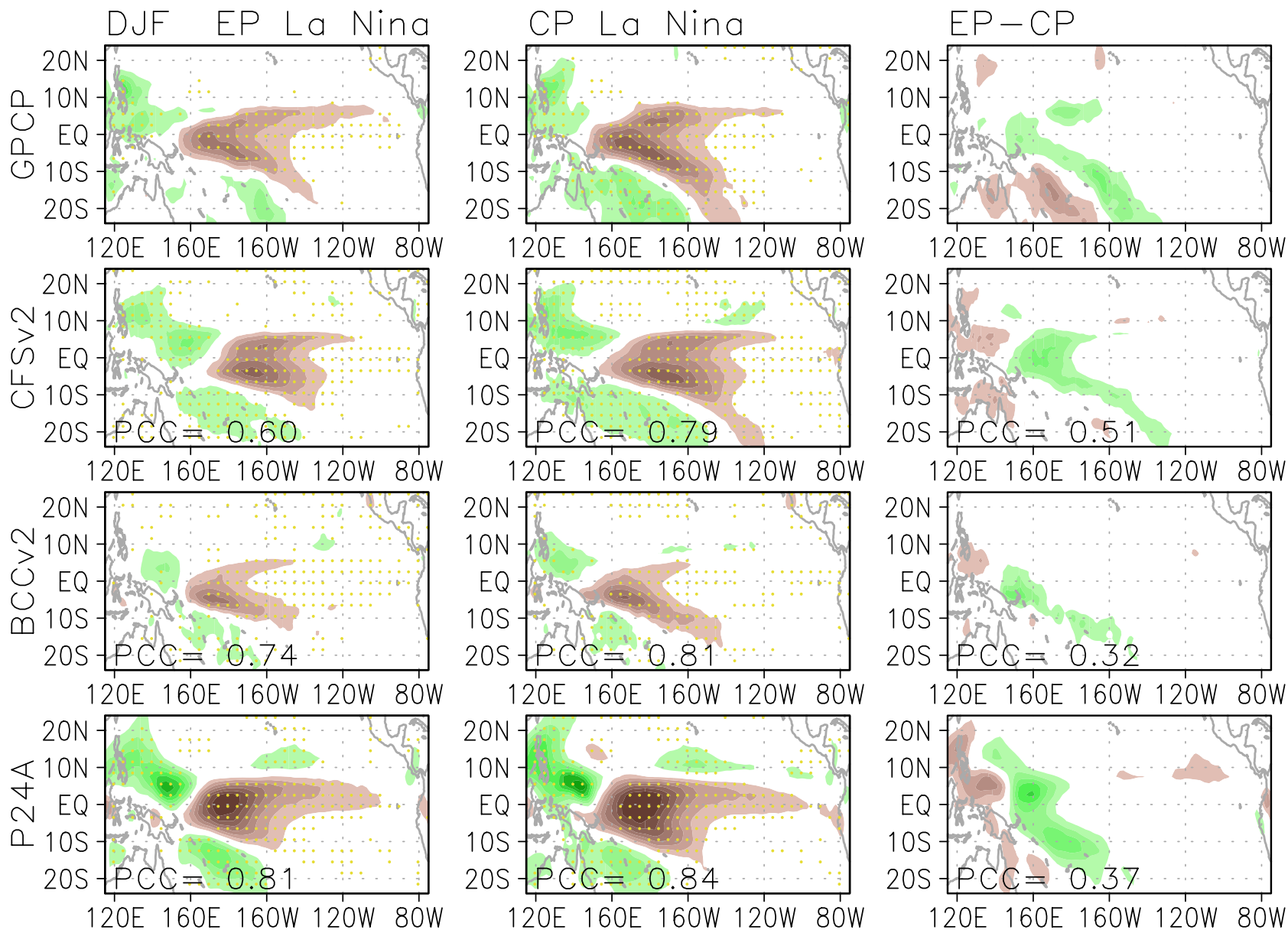

120E 160E 160W 120W 80W

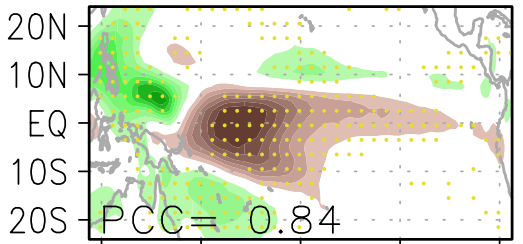

120E 160E 160W 120W 80W
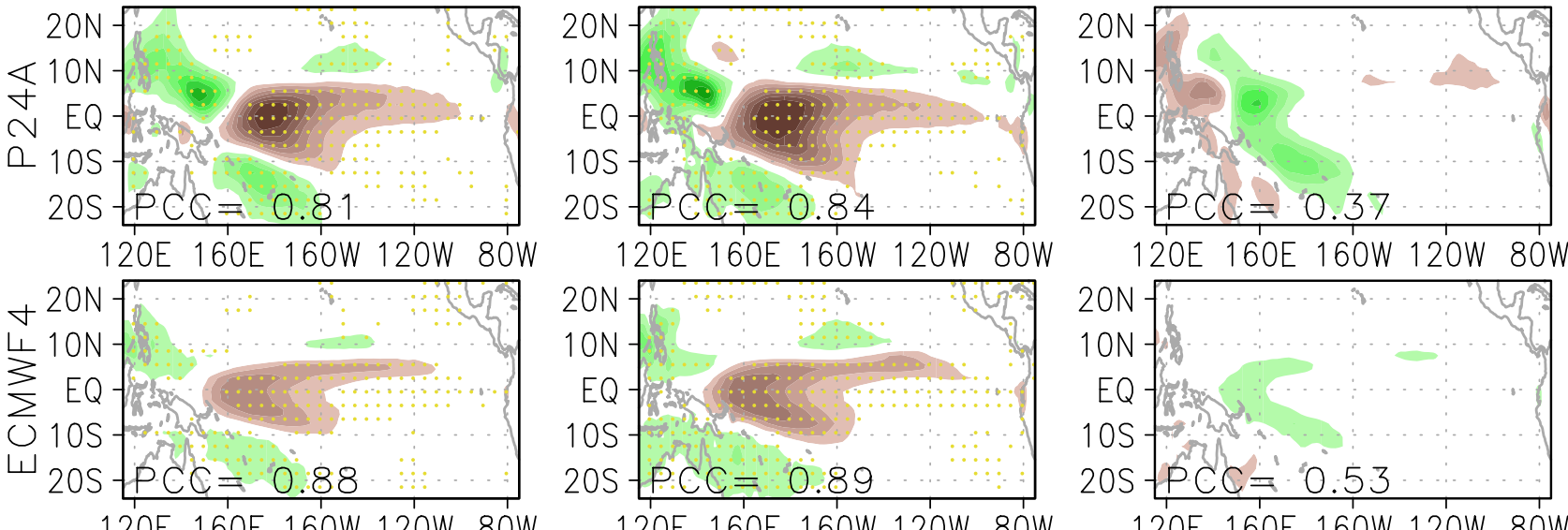

120E 160E 160W 120W 80W
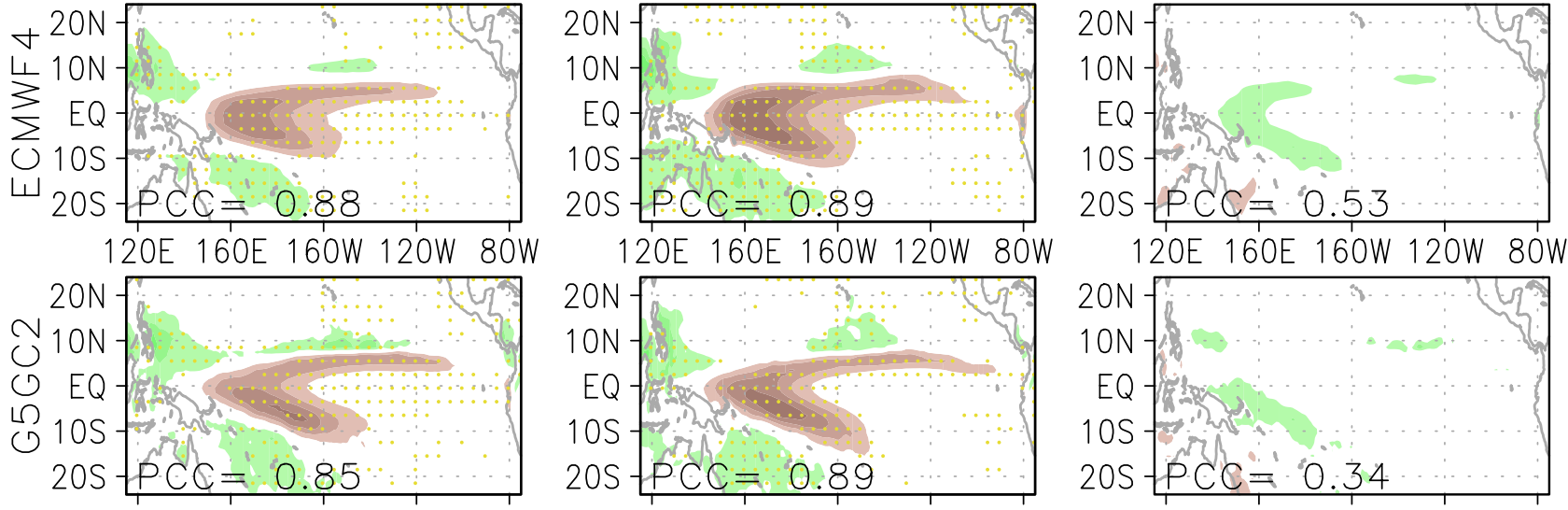

120E 160E 160W 120W 80W

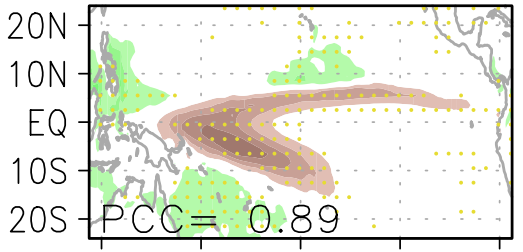

120E 160E 160W 120W 80W
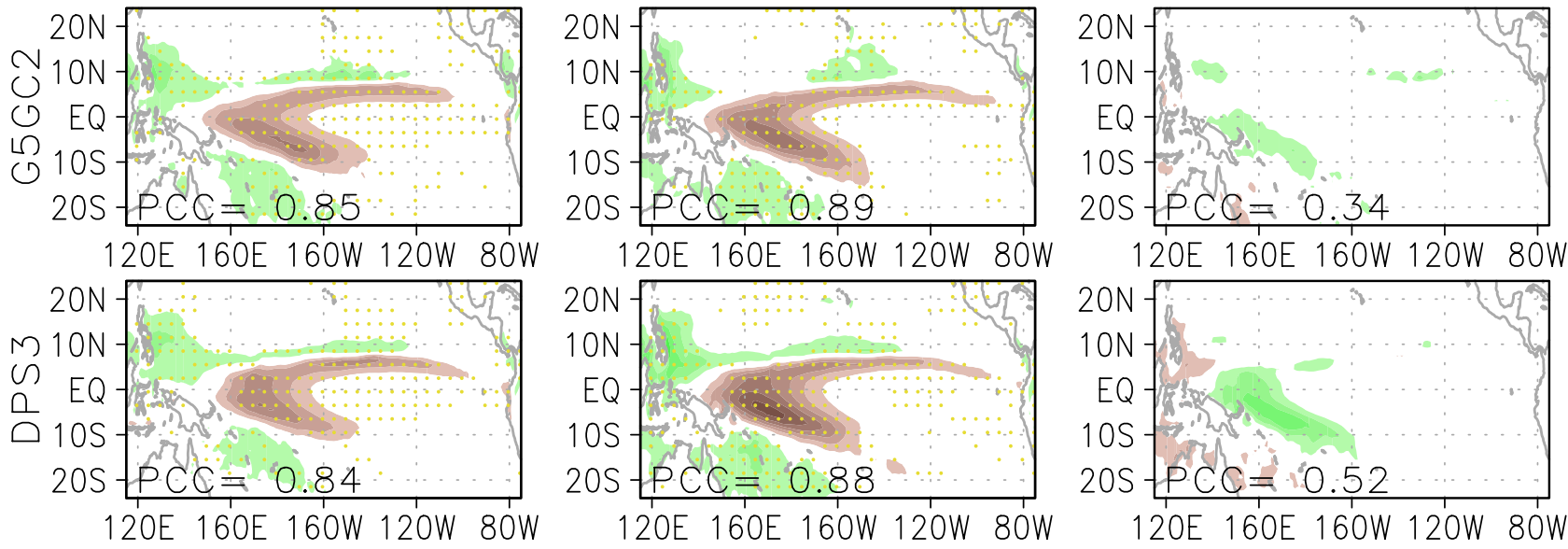

120E 160E 160W 120W 80W
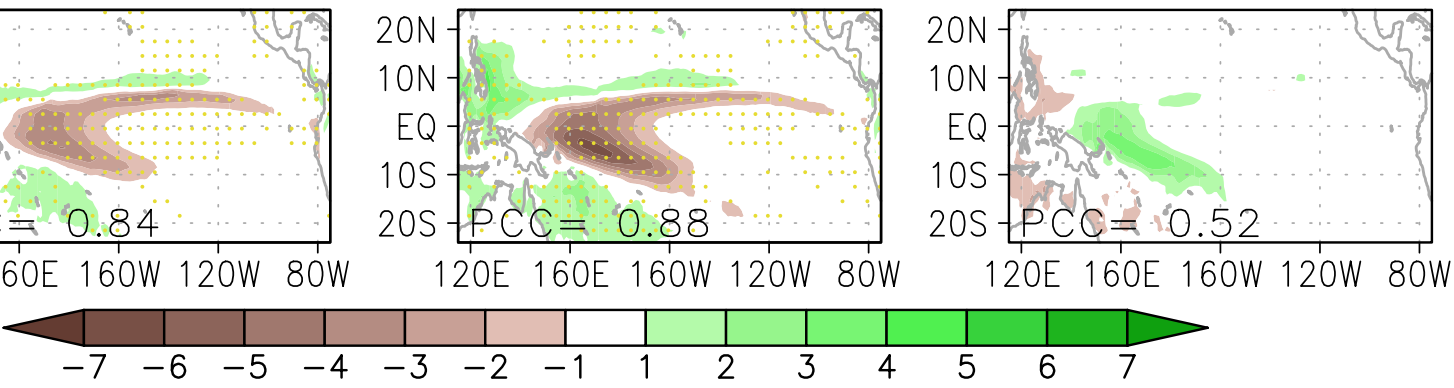

Fig. 7 The same to Fig. 5, but for the two types of La Niña events 
(a) EP EI Nino

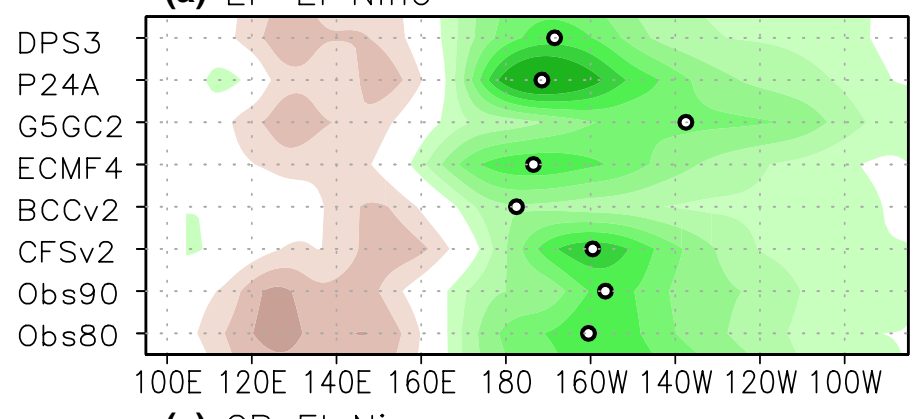

(c) CP El Nino

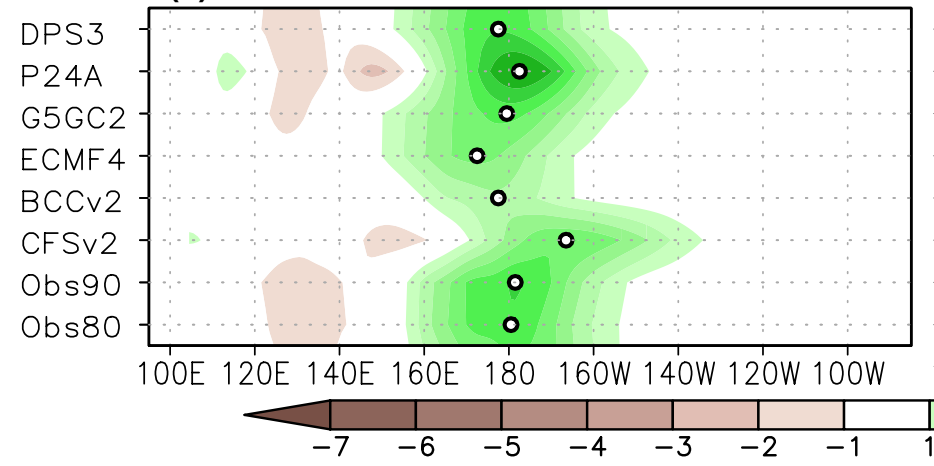

(b) EP La Nina

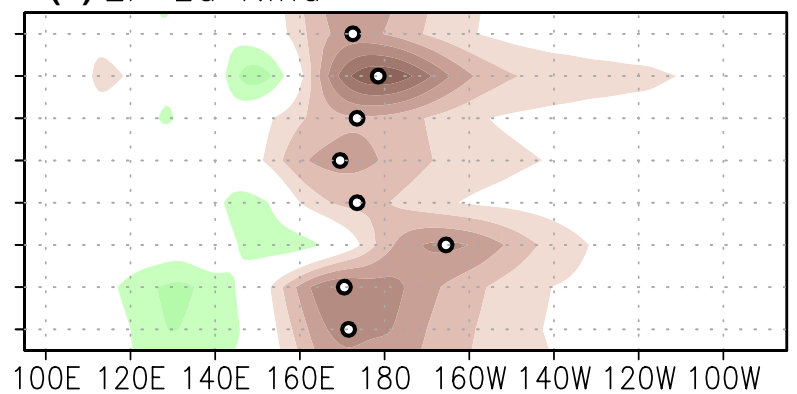

(d) $\mathrm{CP}$ La Nina

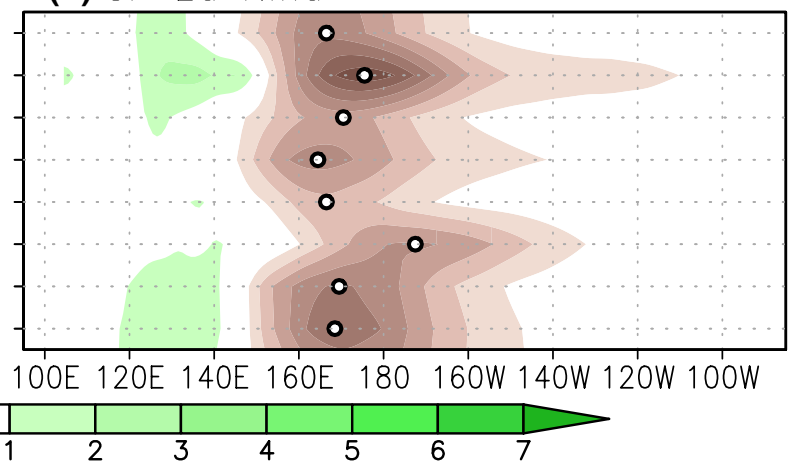

Fig. 8 The same to Fig. 4, but for the equatorial-mean precipitation composites, where Obs 80 and Obs90 denote the GPCP results of 1980-2014 and 1990-2014 periods, respectively

ENSO as has been noted in many studies (e.g., Brönnimann 2007; Fereday et al. 2008; Cagnazzo and Manzini 2009; Butler et al. 2016). Observational studies have also found that this negative NAO response comes mainly from the moderate ENSO events (Toniazzo and Scaife 2006), but studies during the reanalysis period have obtained controversial results regarding whether this response is associated more closely with CP (Graf and Zanchettin 2012) or EP (Sung et al. 2014) events, highlighting the problems of sampling relatively short records. A recent paper examining the response in CMIP5 models supports the association of $\mathrm{CP}$ events with the negative NAO response (Calvo et al. 2015). Some of our models shown here simulate a similar negative NAO response to our observed composite (BCCv2, G5GC2, DPS3) while others produce part of the response (P24A, CFSv2). The ECMWF model does not appear to reproduce the observed response to $\mathrm{CP}$ events and this model also has the weakest teleconnection over the North Pacific.

Figure 10 shows the SLP composites from La Niña events for the observations and model hindcasts. As was seen in the SST and precipitation composites (Fig. 2, 3, 6, and 7) the difference between $\mathrm{EP}$ and $\mathrm{CP}$ events is less pronounced in La Niña events than El Niño events. This is particularly true in the tropics where there is little difference between the SLP responses in EP and CP La Niña events. In the extratropics there are some distinct differences consistent between the $\mathrm{EP}$ and CP events. The Aleutian Low weakens in both event types, but the weakening is greater in $\mathrm{CP}$ events. Although this also occurs in observations it appears more pronounced in the models. The location of the Aleutian Low shifts consistently in the models with CP showing greater increase in SLP further to the west.

In the observations the North Atlantic shows strong differences between the EP and CP La Niña events, with CP events again showing a strong (positive) NAO signal. Only BCCv2 simulate this positive NAO pattern well, whereas P24A shows a more positive NAO signal in EP events. CFSv2 and G5GC2 show much weaker differences between the event types over the North Atlantic than observed, while DPS3 does better. In the southern hemisphere the models capture the observed differences between the event types well. The $\mathrm{CP}$ events show stronger anomalies, with a strong negative center in the southeast Pacific. All the models show this negative anomaly, although P24A shows a stronger anomaly in EP events. In addition, the North Pacific shows only weak differences between the two event types in spite of the differences in the intensity and geophysical positions of the main circulation centers. Still, over the North Pacific the models tend to capture the EP associated circulation patterns better than the $\mathrm{CP}$ ones and the EP-CP differences and the fact that differences are small in the Pacific but large over the Atlantic is consistent with a tropical Atlantic pathway for the teleconnections to the north Atlantic (e.g. Toniazzo and Scaife 2006; Scaife et al. 2017a). 

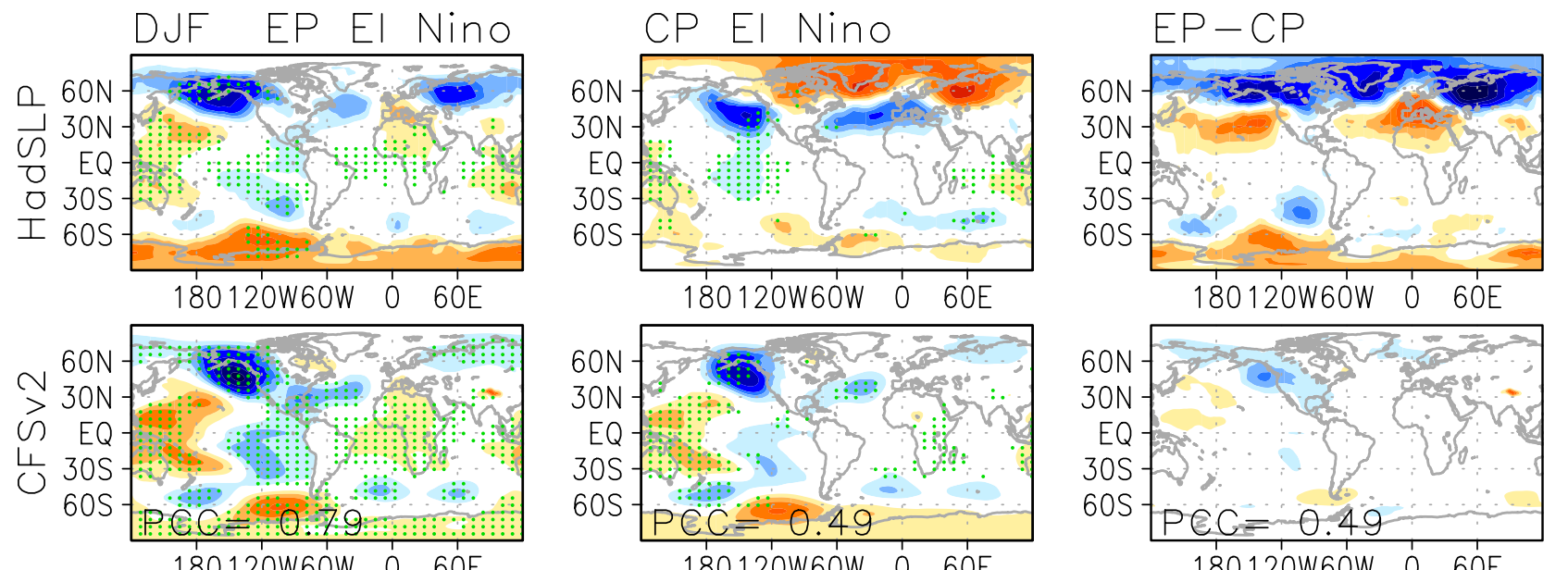

180120W60W O 60E
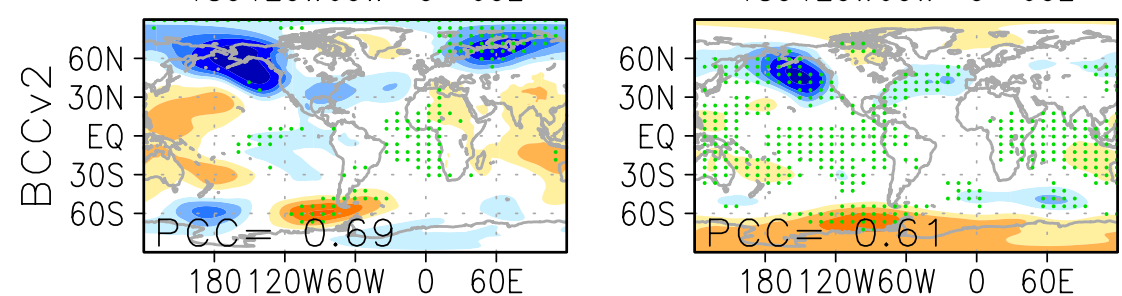

180120W60W O 60E
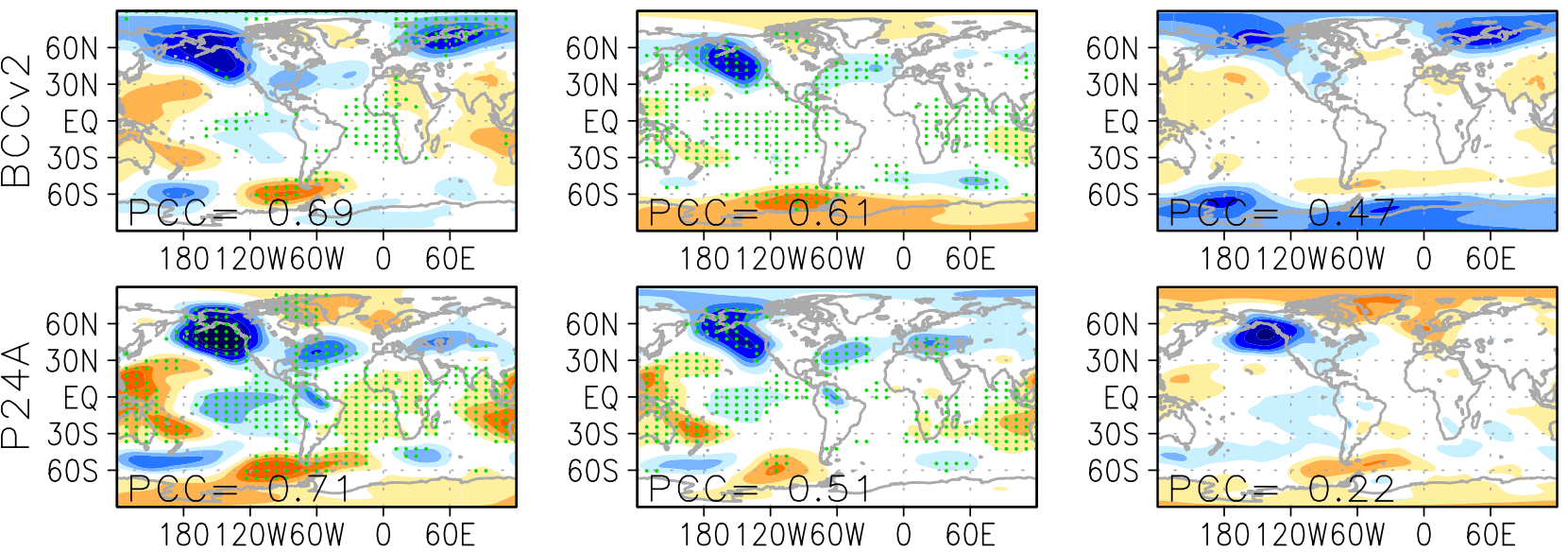

180120W60W O 60E

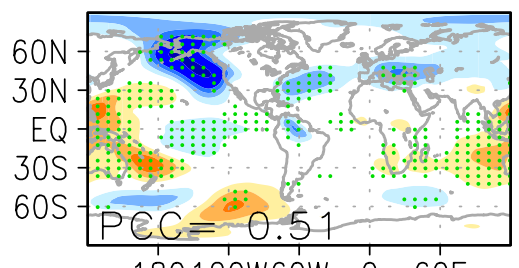

180120W60W O 60E
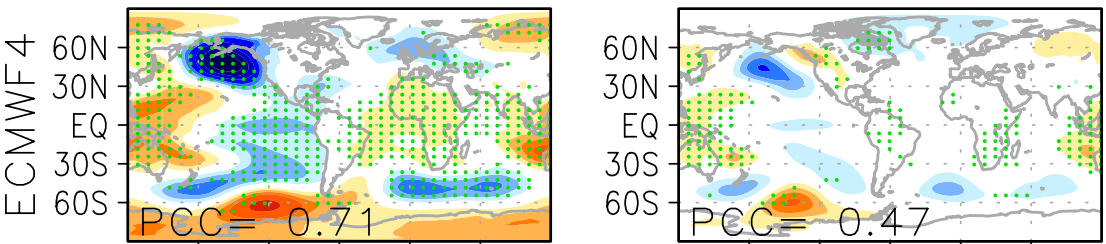

180120W60W O 60E

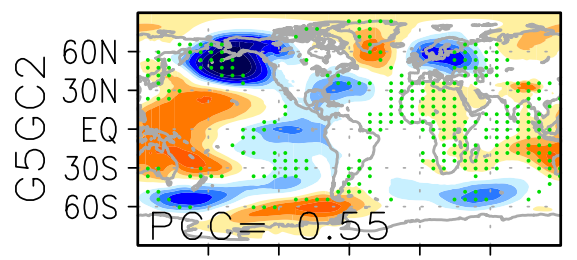

180120W60W O 60E
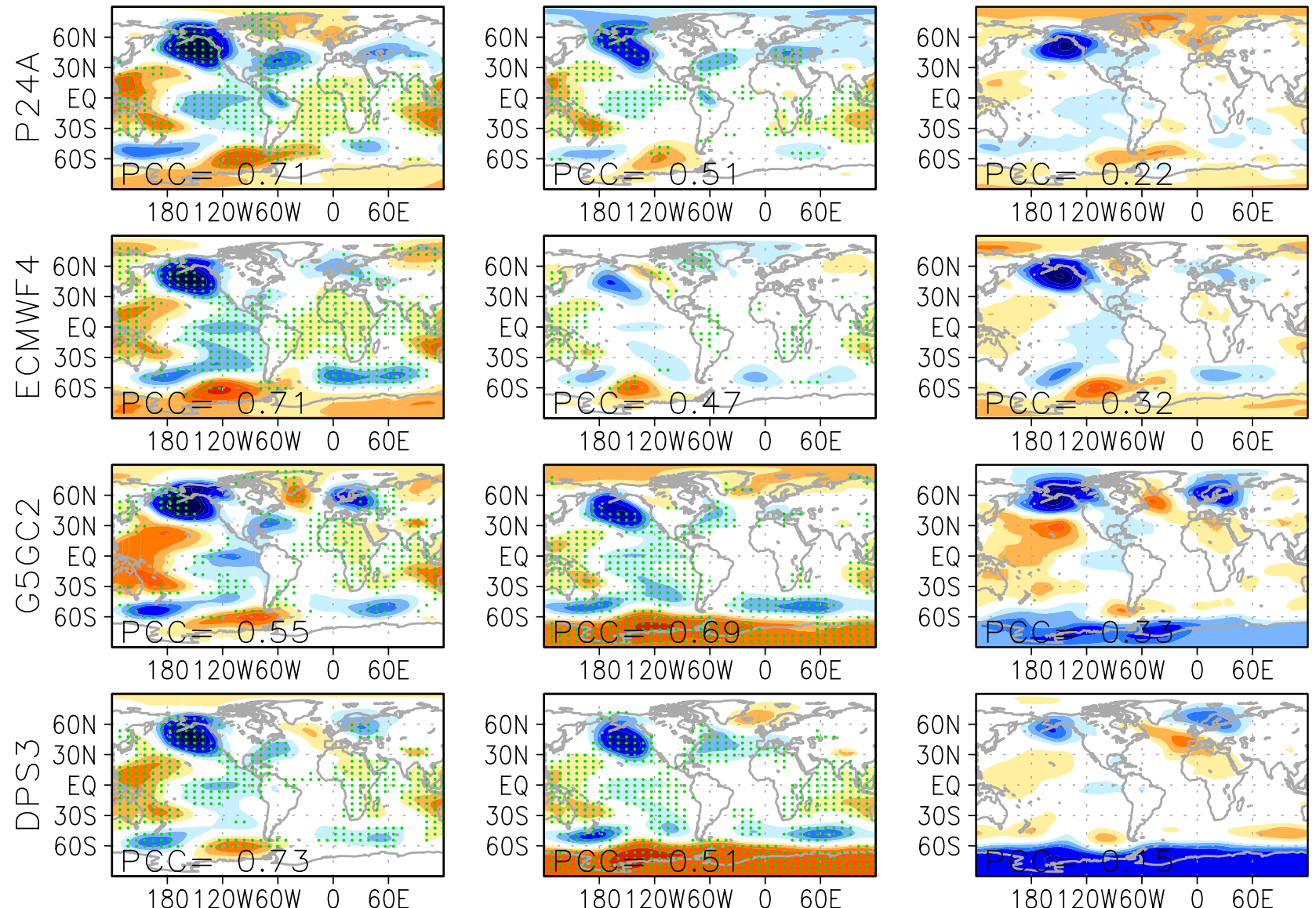

180120W60W O 60E

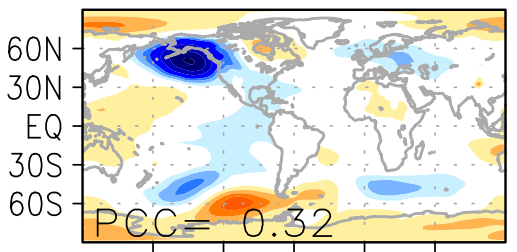

180120W60W O 60E

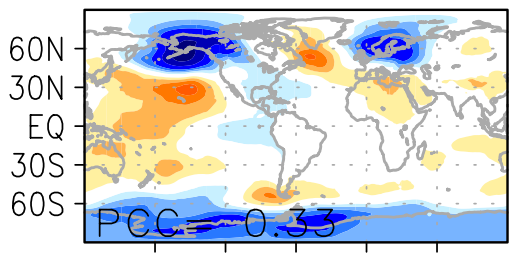

180120W60W O 60E

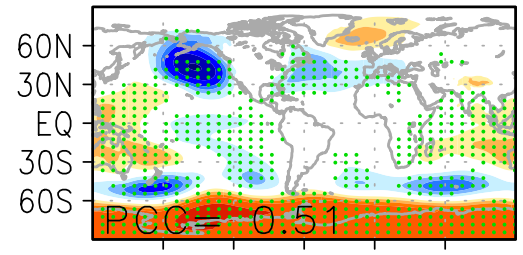

180120W60W O 60E

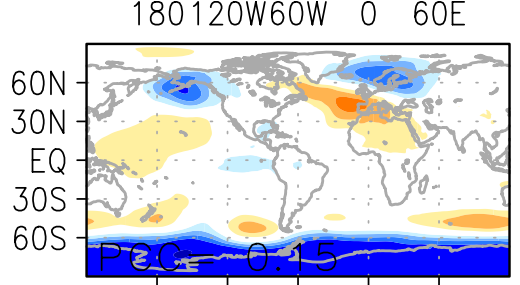

180120W60W O 60E

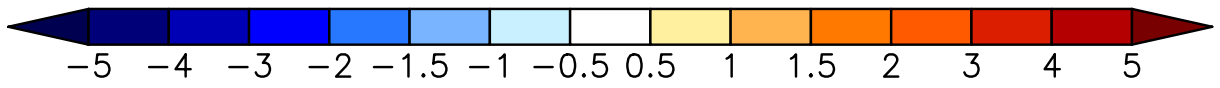


४Fig. 9 Composite patterns of SLP anomalies (Unit: hPa) for the EPtype (left panels) and CP-type (middle panels) El Niño events as well as their differences (right panels) based on the observation (top three panels) and model hindcasts (below panels). Black numbers in panels are PCCs between the model patterns and the corresponding observation pattern. Green dots denote the $t$-test significance at the $95 \%$ confidence level

In this Section, we can see that the model hindcasts have helped us identify the robust teleconnection patterns by using the ensemble data at the shortest lead. Our examination of the extratropical teleconnections to the two ENSO types show that some of the models can reproduce the differences between EP and CP teleconnections. Therefore, through this study we can find out that the ENSO teleconnection is definitely variable with the different ENSO types and phases changing, which provides a good reference for climate prediction.

\section{Prediction skill of different types of ENSO events}

To simply illustrate the main information of evaluation of the event-based canonical patterns, we collect all the PCC skill scores between the observed and forecasted patterns of SST, precipitation, and SLP anomalies, into Fig. 11. It can be clearly seen that, if PCC can measure to some degree the capability of the models in predicting the two types of ENSO events, these models overall give slightly higher skill for the EP than the CP SST patterns for both El Niño and La Niña events, and this is less true for the precipitation patterns. However, such high PCCs do not definitely bring us the high skill that the models distinguish the two types in terms of the EP-CP differences in their canonical SST patterns. It is also clearly seen that the global teleconnection patterns for the CP La Niña and EP La Niña are not always well represented by the models, and that particularly the EP-CP differences are difficult to represent, though some regional circulation patterns can be predicted in different sectors.

We now investigate the prediction skill of the forecast systems in predicting the two types of ENSO events during winter and test whether the year-to-year forecast categories match those observed. Table 3 lists the observed frequencies when the forecast is for either an EP or CP target event for El Niño and La Niña. Here the predicted ENSO events are identified by the same standard as observed using ensemble means of each model and the observed frequencies have been accumulated for all the model forecasts.

As seen in Table 3, importantly, when an El Niño or La Niña event is forecast to occur, there are no incidences of the opposite event occurring (the lower-left and upper-right corners of Table 3 are blank). The skill of differentiating between the sub-types (EP or CP) is more of a challenge for the dynamical model systems, even from this relatively short lead time. Indeed, only half probability can be observed when any given type of El Niño event is forecasted, as shown by the highest numbers along the diagonal of Table 3 . Neutral events are particularly well forecast (successful in $\sim 70 \%$ of cases), with a small tendency for the models to misclassify CP La Niña events as neutral.

The most successful predictions are apparent for the CP La Niña type with over $90 \%$ of those forecasts correctly predicted. However, as discussed in the previouspart, the models tend to under represent the frequency of CP La Niña events and hence there are only eleven such events predicted to occur. This lower sample size means that our models are less confident about the skill of this CP La Niña category, but also suggests that when the model does forecast a $\mathrm{CP}$ La Niña, the dynamical conditions are such that it is very likely to be observed, compared to Table 2. An opposite situation could be used to partially explain why the EP La Niña type has the lowest hit rate with a highest sample size. Possible reason is worthy of being further examined. While many of the differences between the prediction skill of different ENSO types are unlikely to be significant, we conclude that the models can discriminate between ENSO types to a reasonable degree at this lead time as the most likely type occurs more often than any other type in all five phases. Given the different extratropical teleconnections noted above, this could also be useful in real time predictions where the details of the ENSO type can be important (e.g., Scaife et al. 2017b).

\section{MME prediction of detailed SST patterns}

Based on the analyses of the predictability of the canonical patterns and the observed events, we further extend the verification of the prediction for the two ENSO types from the traditional domain-averaged SST anomaly indices to the identified zonal positions of the SST anomaly center of those observed events. With the datasets used in Table 3, we can generate the center longitude indices (CLIs) for the observed and predicted events in terms of the types. Figure 12a first shows the results of verifications of the CLI forecasts by all the models. The EP ENSO events have higher prediction skill than the CP events at 1 month lead. The MME mean forecasts of either all the models or the two "best" models (P24A and DPS3 that generally discriminate the CP type from EP type of canonical patterns) have similar skills, as shown in Fig. 12b, c, and more skillful compared to Fig. 12a, which are likely due to the much smaller sample size. Further, we show the forecast of only DPS3 in Fig. 12d, e, which has relatively satisfactory skill in spite of the apparent errors occurring during the first four events after 2000. As we can see, although the MME mean method does improve prediction skills of their Niño indices to 


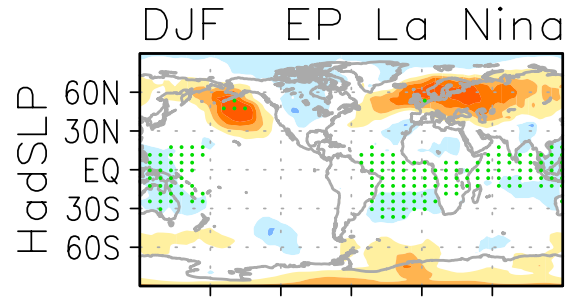

180120W60W O 60E

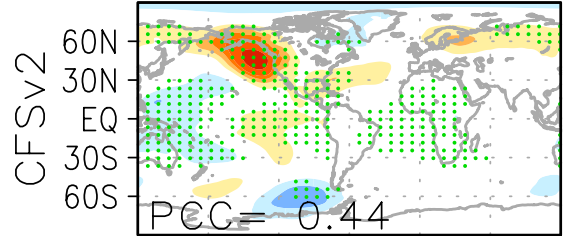

180120W60W O 60E

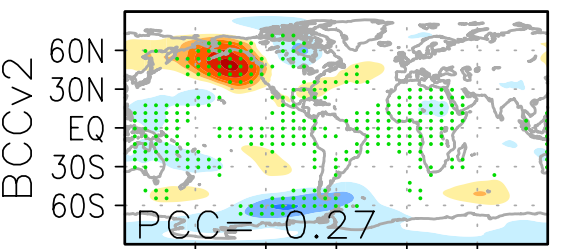

180120W60W O 60E

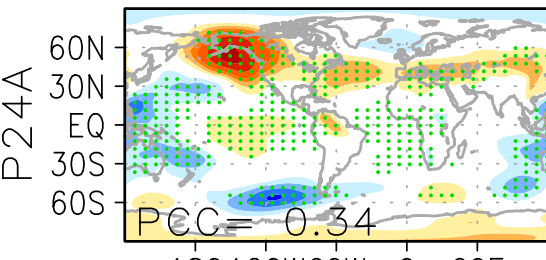

180120W60W O 60E

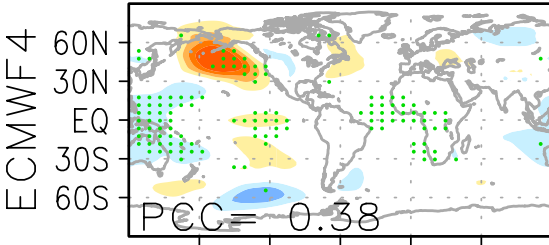

180120W60W O 60E
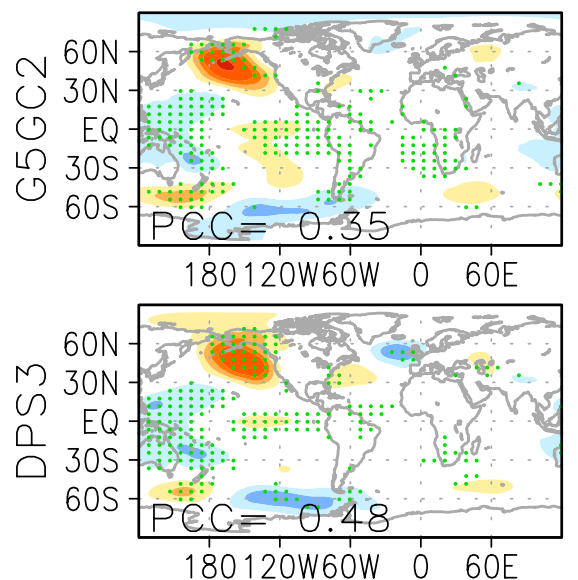

180120W60W O 60E

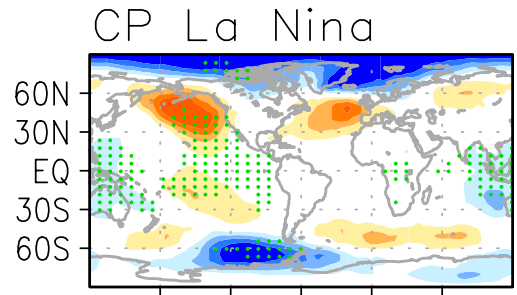

180120W60W O 60E

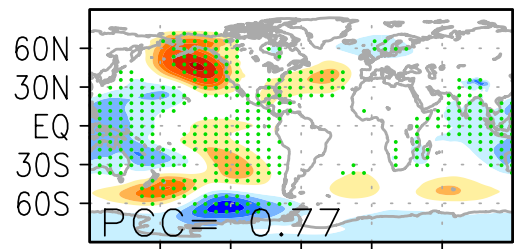

180120W60W O 60E

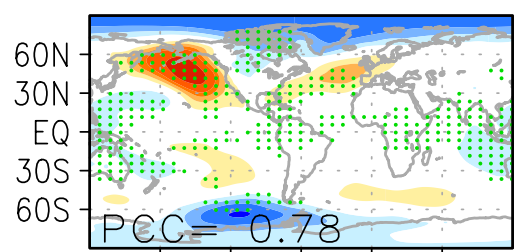

180120W60W O 60E

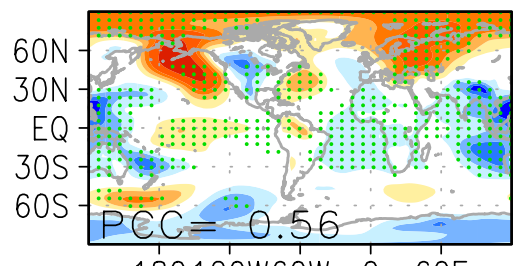

180120W60W O 60E

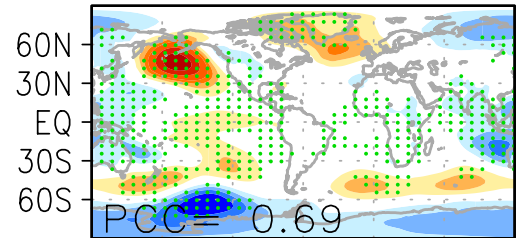

180120W60W O 60E

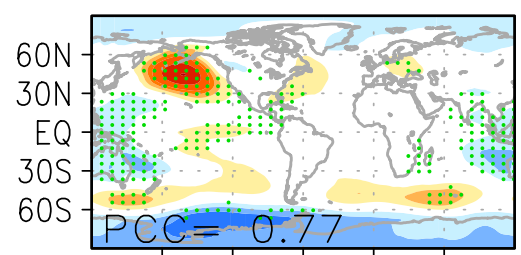

180120W60W O 60E

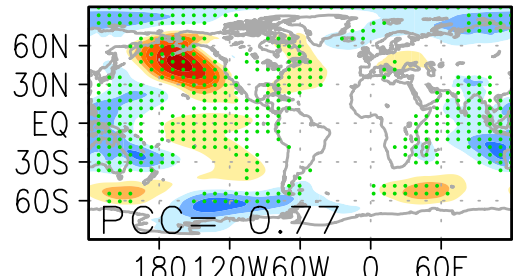

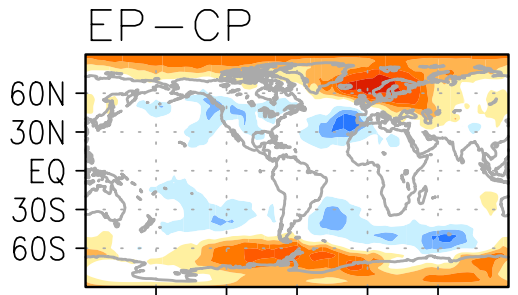

180120W60W O 60E

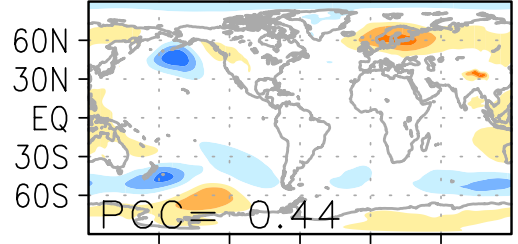

180120W6OW O 60E

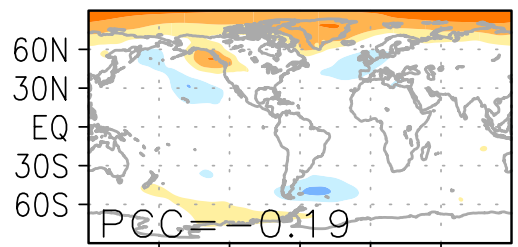

180120W6OW O 60E

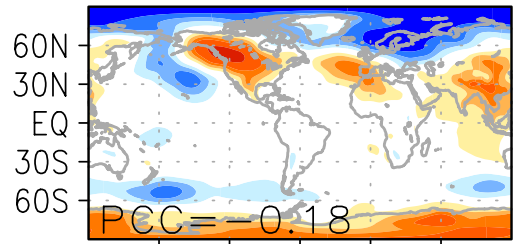

180120W60W O 60E

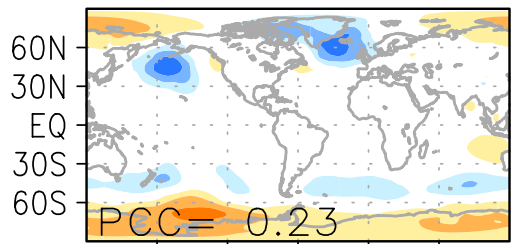

180120W60W O 60E

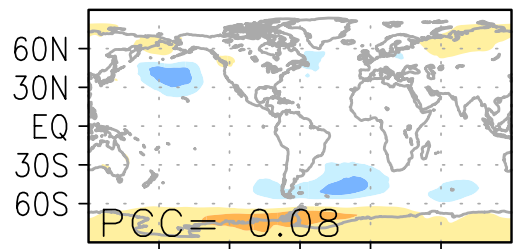

180120W60W O 60E

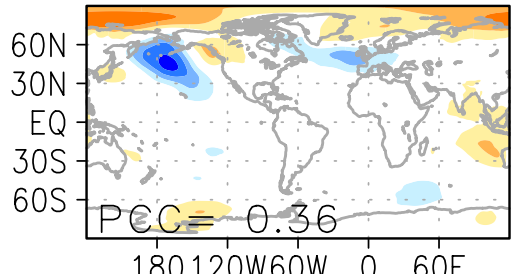

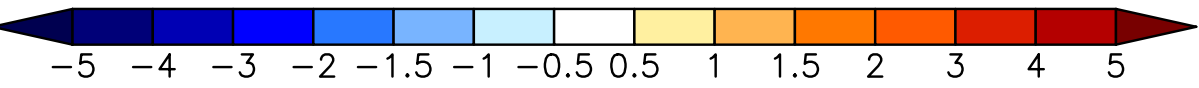

Fig. 10 The same to Fig. 9, but for the two types of La Niña events 
(a) SST EI Niño

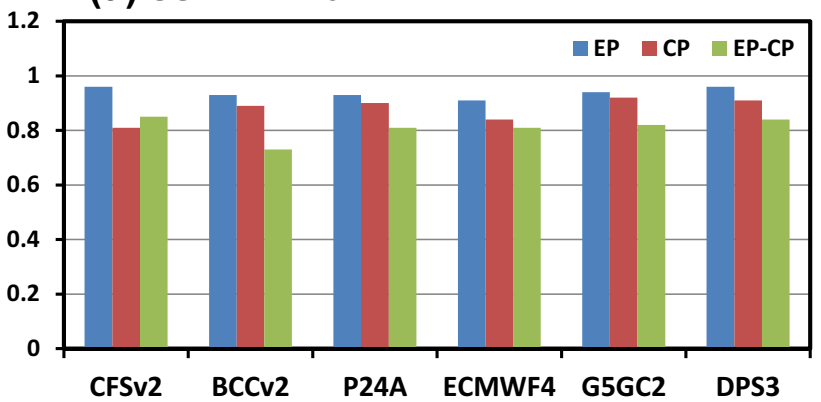

(c) Prec El Niño

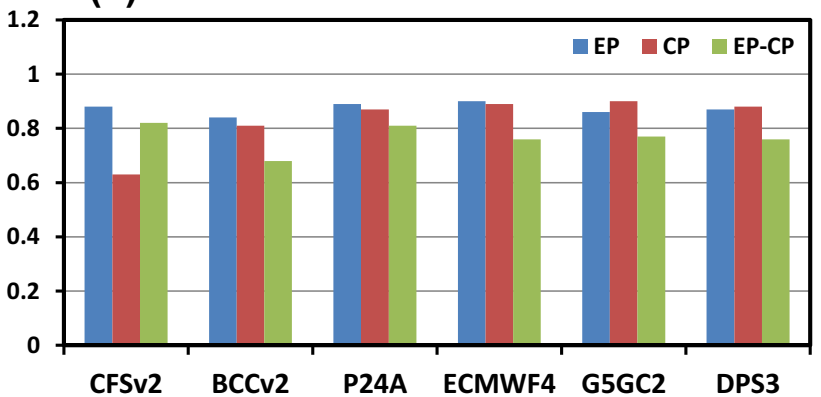

(e) SLP EI Niño

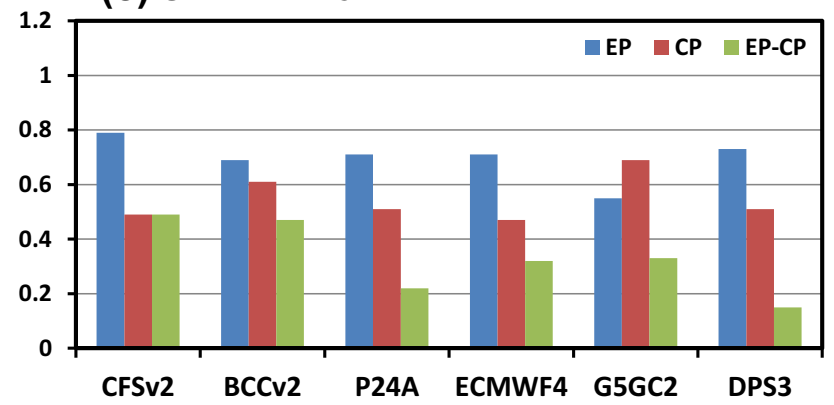

Fig. 11 PCCs between the observed patterns and model forecasted patterns for the EP type (blue), CP type (red), and their differences (green), which are collected from a El Niño SST anomaly patterns in Fig. 2, b La Niña SST anomaly patterns in Fig. 3, c El Niño precipi-

some degree (not shown here, but demonstrated in many previous literatures), distinguishing the center positions of the SST anomaly patterns for the two types would not been expected to realize by the MME mean because most of the models are still difficult to identify the separated centers between the two types. Thus, the MME method has no evident contributions to distinguishing the two types in terms of their center positions, compared to the better models. (b) SST La Niña

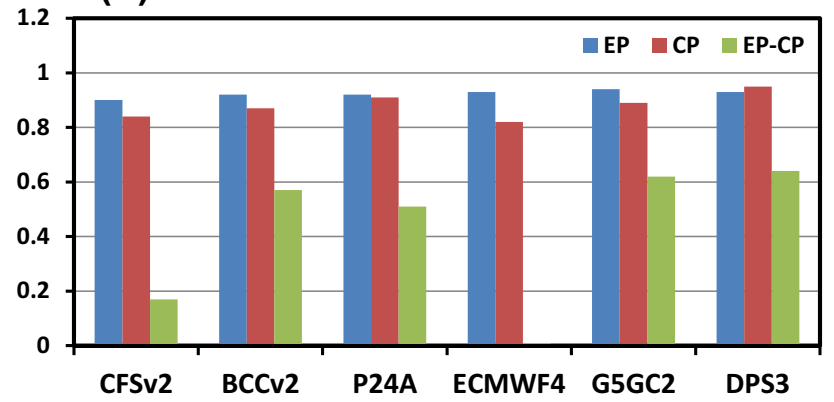

(d) Prec La Niña

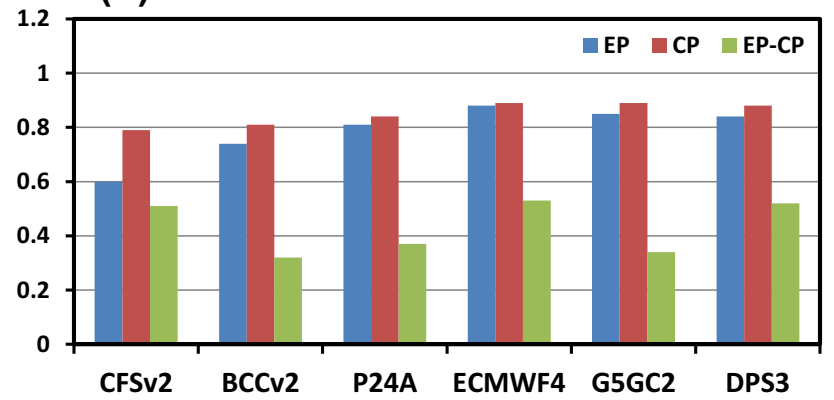

(f) SLP La Niña

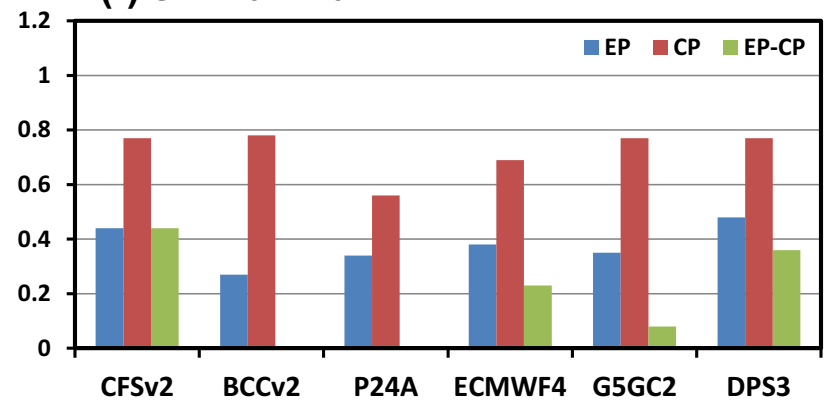

tation anomaly patterns in Fig. 6, d La Niña precipitation anomaly patterns in Fig. 7, e El Niño SLP anomaly patterns in Fig. 9, and $\mathbf{f} \mathrm{La}$ Niña SLP anomaly patterns in Fig. 10, respectively

\section{Summary and discussions}

Different types of ENSO events coexist under the current climate conditions and have significantly distinct remote effects. A few previous studies have focused on the prediction assessments for the two ENSO types using single models (e.g., Hendon et al. 2009; Yang and Jiang 2014; 
Table 3 Contingency table showing the skill of the seasonal forecast systems in predicting the correct type of ENSO

\begin{tabular}{|c|c|c|c|c|c|c|}
\hline \multirow{2}{*}{\multicolumn{2}{|c|}{ All the models }} & \multicolumn{5}{|c|}{ Predicted ENSO types } \\
\hline & & \multirow{2}{*}{$\begin{array}{c}\begin{array}{c}\text { EP El } \\
\text { Niño (39) }\end{array} \\
49 \%\end{array}$} & \multirow{2}{*}{$\begin{array}{c}\text { CP El } \\
\text { Niño (16) } \\
31 \%\end{array}$} & \multirow{2}{*}{$\begin{array}{c}\text { Neutral } \\
(48)\end{array}$} & \multirow{2}{*}{$\begin{array}{c}\text { EP La } \\
\text { Niña (48) }\end{array}$} & \multirow{2}{*}{$\begin{array}{c}\text { CP La } \\
\text { Niña (11) }\end{array}$} \\
\hline \multirow{5}{*}{ 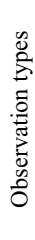 } & EP El Niño & & & & & \\
\hline & CP El Niño & $41 \%$ & $50 \%$ & $8 \%$ & & \\
\hline & Neutral & $10 \%$ & $19 \%$ & $69 \%$ & $17 \%$ & \\
\hline & EP La Niña & & & $8 \%$ & $46 \%$ & $9 \%$ \\
\hline & CP La Niña & & & $15 \%$ & $37 \%$ & $91 \%$ \\
\hline
\end{tabular}

Tabulated are the percentage of events that are observed to occur given the model forecast of a particular EP or CP type for both El Niño and La Niña. The number of forecasts for each type made by all the models is quoted in brackets

Imada et al. 2015). The current study provides a multimodel evaluation for the two types of ENSO events for the SST anomalies, rainfall patterns, and teleconnections, based on six coupled GCMs from different operational centers. Compared to the EOF/indices-based studies (Jeong et al. 2012, 2015), we presented an event-based 1-month-lead predictability evaluation for the two types of ENSO in terms of the El Niño and La Niña events.

It is suggested that a comprehensive evaluation of ENSO predictability for the two types should be based on both continuous and event-based approaches. Our results show that $\mathrm{EP}$ and $\mathrm{CP}$ El Niño events during winter can be distinguished only in 2-3 of our 6 models even at this short lead time, and this is slightly less true for La Niña events, and the EP type tends to has a more realistic zonal positions of SST pattern centers than the CP type. Compared to the SST patterns, the precipitation patterns have smaller differences between the two types especially for La Niña events. The models can reproduce the separation of events for precipitation in some cases, but often show off-equatorial maxima. For teleconnections in the extratropics to the two ENSO types, we can find out that they are definitely variable with the different ENSO types and phases changing. We confirmed that our EP events, which sample several strong El Niño events, can drive strong Atlantic wave-trains while our composite of $\mathrm{CP}$ events produce a negative NAO response, consistent with
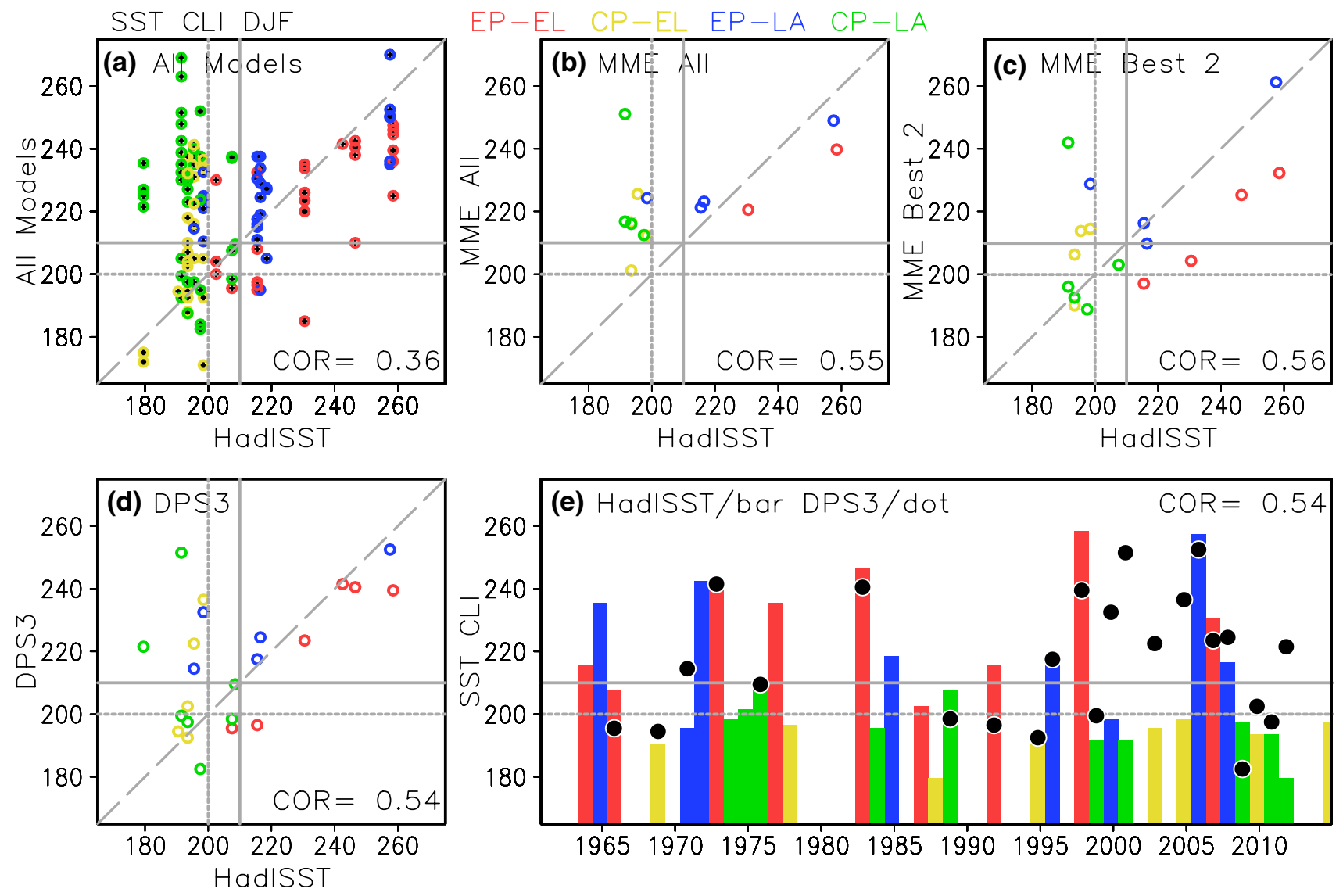

Fig. 12 Scatter plots of the observed CLIs (HadISST, x-axis) and the model forecasted CLIs (y-axis) of a all models, $\mathbf{b}$ MME mean of all models, $\mathbf{c}$ MME mean of the P24A and DPS3, $\mathbf{d}$ the DPS3 and $\mathbf{e}$ the

bar (HadISST)-dot (DPS3) plot in which the symbols and bars are for the events of the EP El Niño (red), CP El Niño (yellow), EP La Niña (blue), and CP La Niña (green) 
(a) EP EI Nino

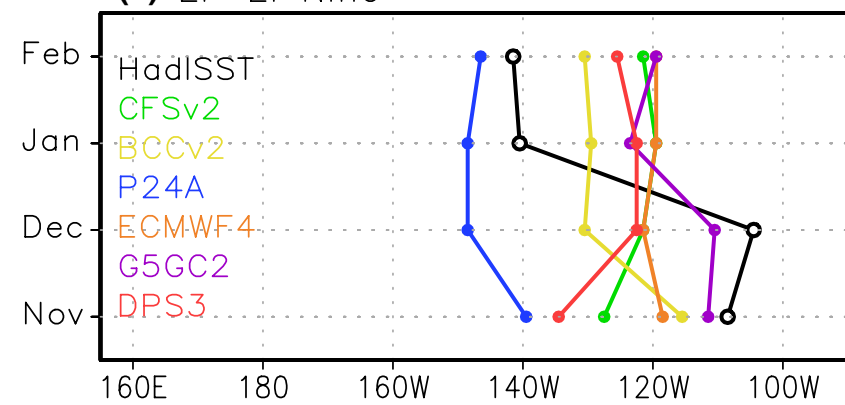

(c) CP El Nino

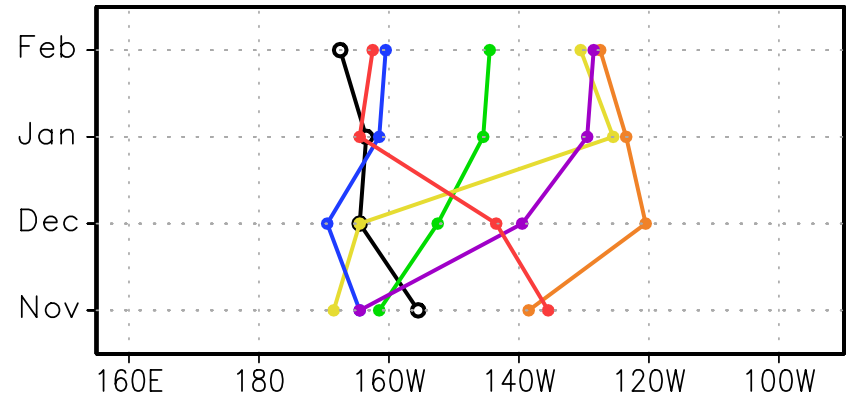

(b) EP La Nina

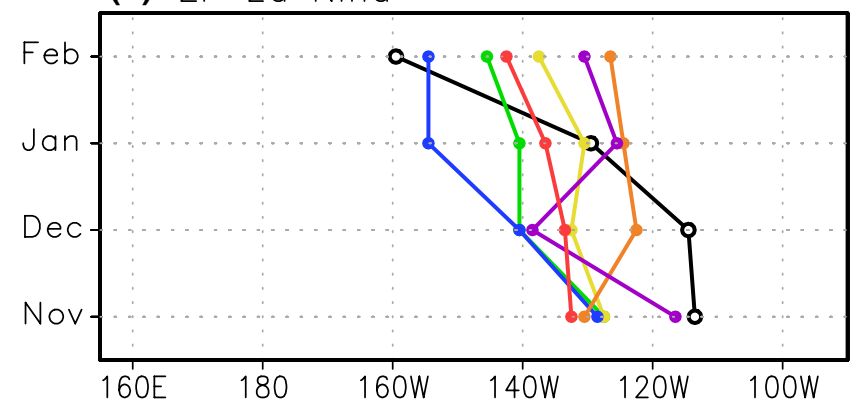

(d) CP La Nina

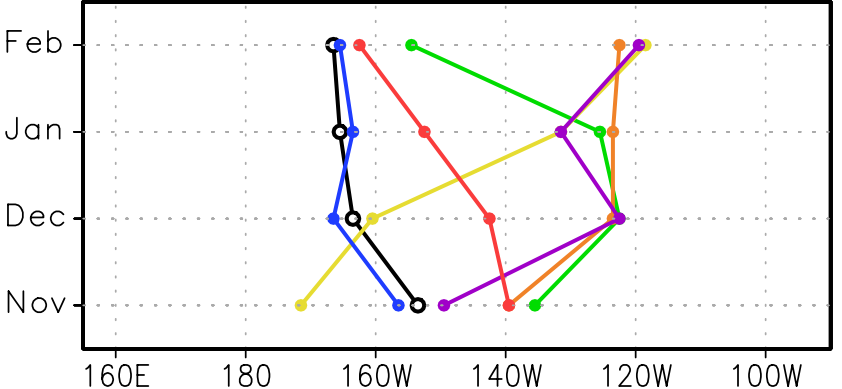

Fig. 13 Evolutions of the composite center longitudes of the HadISST (1980-2014) and the initialized (Nov) and forecasted (Dec-Jan-Feb) SST anomaly patterns (solid lines) using the events of the EP El Niño (a), EP La Niña (b), CP El Niño (c), and CP La Niña (d)

the observed CP composite in this study. However, why the extratropical teleconnections show such large differences from quite similar tropical precipitation patterns between the two La Niña types, is still an open question. Our results show that some of the models can reproduce the differences between the observed canonical teleconnections patterns at 1-month lead.

This study examined predictability of the two ENSO types in dynamical predictions near their peak in the wintertime, at seasonal lead time. It would be interesting in future work to determine the longest lead time that the main differences between the two types of ENSO events can be reasonably predicted as shown for some single models (e.g., Hendon et al. 2009; Yang and Jiang 2014). Our results also showed that EP ENSO indices are overall better predicted than CP ENSO indices in the six models, which is consistent with previous studies (e.g., Yang and Jiang 2014; Imada et al. 2015). Further, the event-based evaluations of model predictions show that the EP El Niño event has the same level hit rate with the CP El Niño and the CP La Niña event has much higher hit rate than the EP La Niña. Explanation of this interesting result will require further study but may well be related to amplitude. However, this result is still controversial as Kim et al. (2009) concluded that EP events are less predictable than CP events based on analysis of relative persistence of the traditional SST indices, and Ren et al. (2016) found that the CP type has a much weaker and more delayed persistence barrier than the EP type. Moreover, it would also be interesting to examine the dynamical processes and mechanisms for the generation and maintenance of the two ENSO types in the models.

We found that the MME mean of the models is not able to improve forecast skill of center longitude index of the SST patterns and distinguish the two ENSO types, though prediction skill of the Niño indices can be increased. In this case, we should note that the MME mean has no evident contribution to prediction of the zonal positions of SST anomaly centers between the two ENSO types. This is because only a few coupled GCMs in the model group are able to distinguish the longitudinal differences between the two types of events. Moreover, La Niña events are less well separated in terms of the two types in both the observation and most model predictions. Nevertheless, we note here that at least some dynamical models are able to predict more than the average ENSO spatial pattern, at least at short lead time. Recent studies showed that the analogue-based correction of the CFSv2 and BCCv2 can significantly improve the dynamical ENSO predictions in terms of the two types (Ren et al. 2017; Liu and Ren 2017), providing an alternative way to make prediction of the two ENSO types better than original dynamical model predictions.

Finally, we come back to a key question why the majority of these operational models have difficulty in predicting the center positions of winter SST anomaly patterns between the different ENSO types only at one month lead? Fig. 13 
presents the evolution of the center positions of the composite SST patterns of different models with lead time for each ENSO type. Although the maximum SSTs are initially anchored near to the observations as a result of initialization of the models, this information is quickly lost during the following few months in most of the models. Particularly, such a quick dissipation of initial distinctions generally occurs more in the CP types of El Niño and La Niña than the EP ones. For example, G5GC2 almost has the best initialized center positions of the SST anomaly patterns in the different types but are visible to usually evolve into quite different ways compared to the observations. On one hand, this suggests that the initialization processes of subsurface ocean rather than the SST only could be quite important for the models to capture the initial signals of the ENSO types. On the other hand, this result indicates that, except the model initialization, model performance including drift and the ability to represent ENSO types may be the key aspect that limit the predictability of the winter two types of ENSO events. Therefore, more efforts are required to improve the performance of the climate models in distinguishing the two types of ENSO and additional investigation of thermocline and current anomalies may provide important information in explaining why some models fails to predict the ENSO types.

Acknowledgements This work is jointly supported by National Key R\&D Program of China (2017YFC1502302), China Meteorological Special Project (GYHY201506013), and National Natural Science Foundation of China (Grants 41606019 and 41405080). The contributors (AAS, ND, VT, SI, DS, MV, CM) are supported by the UK-China Research \& Innovation Partnership Fund through the Met Office Climate Science for Service Partnership (CSSP) China as part of the Newton Fund. The authors are grateful to three anonymous reviewers for their insightful comments to improve the quality of the paper.

Open Access This article is distributed under the terms of the Creative Commons Attribution 4.0 International License (http://creativeco mmons.org/licenses/by/4.0/), which permits unrestricted use, distribution, and reproduction in any medium, provided you give appropriate credit to the original author(s) and the source, provide a link to the Creative Commons license, and indicate if changes were made.

\section{References}

Adler RF, Huffman GJ, Chang A, Ferraro R, Xie P, Janowiak J, Rudolf B, Schneider U, Curtis S, Bolvin D, Gruber A, Susskind J, Arkin $P$ (2003) The version 2 global precipitation climatology project (GPCP) monthly precipitation analysis (1979-present). J Hydrometeorol 4:1147-1167

Allan RJ, Ansell TJ (2006) A new globally complete monthly historical mean sea level pressure data set (HadSLP2). J Clim 19:1850-2004 $5816-5842$.

Ashok H, Yamagata T (2009) Climate change: the El Niño with a difference. Nature 461:481-484. https://doi.org/10.1038/461481a
Ashok K, Behera SK, Rao SA, Weng H, Yamagata T (2007) El Niño Modoki and its possible teleconnection. J Geophys Res 112:C11007. https://doi.org/10.1029/2006JC003798

Barnston AG, Tippett MK, L'Heureux ML et al (2012) Skill of realtime seasonal ENSO model predictions during 2002-11: is our capability increasing? Bull Am Meteorol Soc 93(5):631-651

Bell CJ, Gray LJ, Charlton-Perez AJ, Joshi MM, Scaife AA (2009) Stratospheric communication of El Niño teleconnections to European winter. J Clim 22(15):4083-4096

Brönnimann S (2007) The impact of El Niño-Southern Oscillation on European climate. Rev Geophys 45:RG3003. https://doi. org/10.1029/2006RG000199

Brönnimann S, Xoplaki E, Casty C, Pauling A, Luterbacher J (2007) ENSO influence on Europe during the last centuries. Clim Dyn 28:181-197. https://doi.org/10.1007/s00382-006-0175-z

Butler AH et al (2016) The Climate historical forecast project: do stratosphere-resolving models make better seasonal climate predictions in boreal winter? Quart J Roy Met Soc 142:1413-1427

Cagnazzo C, Manzini E (2009) Impact of the stratosphere on the winter tropospheric teleconnections between ENSO and the North Atlantic and European region. J Clim 22(5):1223-1238. https://doi.org/10.1175/2008JCLI2549.1

Calvo N, Iza M, Hurwitz MM, Manzini E, Peña-Ortiz C, Butler AH, Cagnazzo C, Ineson S, Garfinkel CI (2017) Northern hemisphere stratospheric pathway of different El Niño flavors in CMIP5 models. J Clim. https://doi.org/10.1175/ JCLI-D-16-0132.1

Cane MA, Zebiak SE, Dolan SC (1986) Experimental forecasts of El Niño. Nature 321:827-832

Chen D, Zebiak SE, Busalacchi AJ et al (1995) An improved procedure for El Niño forecasting: Implications for predictability. Science 269:1699-1702

Chen D, Cane MA, Kaplan A et al (2004) Predictability of El Niño over the past 148 years. Nature 428:733-736. https://doi. org/10.1038/nature02439

Cheng YJ, Tang YM, Zhou XB et al (2010) Further analysis of singular vector and ENSO predictability in the Lamont model-part I: singular vector and the control factors. Clim Dyn 35:807-826

Davey MK, Brookshaw A, Ineson S (2014) The probability of the impact of ENSO on precipitation and near-surface temperature. Clim Risk Manag 1:5-24. https://doi.org/10.1016/j. crm.2013.12.002

Dunstone N, Smith D, Scaife AA et al (2016) Skilfulpredictions of the winter North Atlantic Oscillation one year ahead. Nat GeoSci 9:809-814

Feng J, Li J (2011) Influence of El Niño Modoki on spring rainfall over south China. J Geophys Res 116:D13102. https://doi. org/10.1029/2010JD015160

Feng J, Wang L, Chen W, Fong SK, Leong KC (2010) Different impacts of two types of Pacific Ocean warming on Southeast Asian rainfall during boreal winter. J Geophys Res 115:D24122. https://doi.org/10.1029/2010JD014761

Fereday DR, Knight JR, Scaife AA, Folland CK, Philipp A (2008) Cluster analysis of North Atlantic-European circulation types and links with tropical Pacific Sea surface temperatures. J Clim 21:3687-3703

Graf H-F, Zanchettin D (2012) Central Pacific El Niño, the "subtropical bridge," and Eurasian climate. J Geophys Res 117(D1):D01102. https://doi.org/10.1029/2011JD016493

Greatbatch RJ, Lu J, Peterson KA (2004) Nonstationary impact of ENSO on Euro-Atlantic winter climate. Geophys Res Lett 31:L02208. https://doi.org/10.1029/2003GL018542

Ham Y-G, Kug J-S (2012) How well do current climate models simulate two types of El Niño? Clim Dyn 39:383-398. https://doi. org/10.1007/s00382-011-1157-3 
Ham Y-G, Kug J-S (2015) Improvement of ENSO simulation based on intermodel diversity. J Climate 28(3):998-1015

Ham Y-G, Kug J-S, Kang I-S (2009) Optimal initial perturbations for El Niño ensemble prediction with ensemble Kalman filter. Clim Dyn 33(7):959-973. https://doi.org/10.1007/s00382-009-0582

Hendon HH, Lim E, Wang G, Alves O, Hudson D (2009) Prospects for predicting two flavors of El Niño. Geophys Res Lett 36:L19713. https://doi.org/10.1029/2009GL040100

Imada Y, Tatabe H, Ishii M, Chikamoto Y, Mori M, Arai M, Watanabe M, Kimoto M (2015) Predictability of two types of El Niño assessed using an extended seasonal prediction system by MIROC. Mon Wea Rev 143:4597-4617

Ineson S, Scaife AA (2009) The role of the stratosphere in the European climate response to El Niño. Nat Geosci 2:32-36. https:// doi.org/10.1038/ngeo381

Izumo T, Vialard J, Lengaigne $M$ et al (2010) Influence of the state of the Indian Ocean Dipole on the following year's El Niño. Nat Geosci 3(3):168-172. https://doi.org/10.1038/ngeo760

Jeong H-I, Lee DY, Ashok K, Ahn J-B, Lee J-Y, Luo J-J, Schemm J-KE, Hendon HH, Braganza K, Ham Y-G (2012) Assessment of the APCC couple MME suite in predicting the distinctive climate impacts of two flavors of ENSO during boreal winter. Clim Dyn 39:475-493. https://doi.org/10.1007/s00382-012-1359-3

Jeong H-I, Ahn J-B, Lee J-Y, Alessandri A, Hendon HH (2015) Interdecadal change of interannual variability and predictability of two types of ENSO. Clim Dyn 44:1073-1091. https://doi.org/10.1007/ s00382-014-2127-3

Jia X, Lin H, Lee J-Y, Wang B (2012) Season-dependent forecast skill of the dominant atmospheric circulation patterns over the PacificNorth American region. J Climate 25:7248-7265

Jin EK, Kinter JL, Wang B et al (2008) Current status of ENSO prediction skill in coupled ocean-atmosphere models. Clim Dyn 31(6):647-664

Kang I-S, Kug J-S (2000) An El-Niño prediction system using an intermediate ocean and a statistical atmosphere. Geophys Res Lett 15:1167-1170

Kao HY, Yu JY (2009) Contrasting eastern-Pacific and centralPacific types of El Niño. J Clim 22:615-632. https://doi. org/10.1175/2008JCLI2309.1

Kim, H-M., PJ, Webster, Curry JA (2009) Impact of shifting patterns of Pacific Ocean warming on north Atlantic tropical cyclones. Science 325:77-80. https://doi.org/10.1126/science.1174062

Kirtman PB (2003) The COLA anomaly coupled model: Ensemble ENSO prediction. Mon Wea Rev 131:2324-2341

Knight JR, Andrews MB, Smith DM, Arribas A, Colman AW, Dunstone NJ, Eade R, Hermanson L, MacLachlan C, Peterson KA, Scaife AA, Williams A (2014) Predictions of climate several years ahead using an improved decadal prediction system. J Clim 27:7550-7567. https://doi.org/10.1175/JCLI-D-14-00069.1

Kug J-S, Ham Y-G (2011) Are there two types of La Niña? Geophys Res Lett 38:L16704. https://doi.org/10.1029/2011GL048237

Kug J-S, Jin F-F, An S-I (2009) Two types of El Niño events: Cold tongue El Niño and warm pool El Niño. J Clim 22:1499-1515. https://doi.org/10.1175/2008JCLI2624.1

Larkin NK, Harrison DE (2005a) On the definition of El Niño and associated seasonal average U.S. weather anomalies. Geophys Res Lett 32:L13705. https://doi.org/10.1029/2005GL022738

Larkin NK, Harrison DE (2005b) Global seasonal temperature and precipitation anomalies during El Niño autumn and winter. Geophys Res Lett 32:L16705. https://doi.org/10.1029/2005GL022860

Latif M, Anderson D, Barnett T et al (1998) A review of the predictability and prediction of ENSO. J Geophys Res 103:14375-14393

Lee J-Y, Ha K-J (2015) Understanding of interdecadal changes in variability and predictability of the Northern Hemisphere summer tropical-extratropical teleconnection. J Clim 28:8634-8647
Lee J-Y, Wang B, Kang I-S, Shukla J, Kumar A, Kug J-S, Schemm J, Juo J-J, Yamagata T, Fu X, Alves O, Stern B, Rosati T, Park CK (2010) How are seasonal prediction skills related to models performance on mean state and annual cycle? Clim Dyn 35: 267-283

Lim EP, Hendon HH, Hudson D, Wang G, Alves O (2009) Dynamical forecast of inter-El Niño variations of tropical SST and Australian spring rainfall. Mon Wea Rev 137:3796-3810. https://doi. org/10.1175/2009MWR2904.1

Liu Y, Ren H-L (2017) Improving ENSO prediction in CFSv2 with an analogue-based correction method. Inter J Clim 37(15):50355046. https://doi.org/10.1002/joc.5142

Luo J-J, Masson S, Behera S et al (2005) Seasonal climate predictability in a coupled OAGCM using a different approach for ensemble forecasts. J Clim 18:4474-4497

Luo J-J, Masson S, Behera SK et al (2008) Extended ENSO predictions using a fully coupled ocean-atmosphere model. J Clim 21(1):84-93

MacLachlan C, Arribas A, Peterson KA, Maidens A, Fereday D, Scaife AA, Gordon M, Vellinga M, Williams A, Comer RE, Camp. J, Xavier P, Madec G (2015) Global seasonal forecast system version 5 (GloSea5): a high resolution seasonal forecast system. Q J R Meteorol Soc 141(689):1072-1084. https://doi.org/10.1002/ qj.2396

Mason SJ, Goddard L (2001) Probabilistic precipitation anomalies associated with ENSO. Bull Am Meteorol Soc 82:619-638

McPhaden MJ, Lee T, McClurg D (2011) El Niño and its relationship to changing background conditions in the tropical Pacific Ocean. Geophys Res Lett 38:L15709

Molteni F, Stockdale T, Balmaseda M, Balsamo G, Buizza R, Ferranti L, Magnusson L, Mogensen K, Palmer T, Vitart F (2011) The new ECMWF seasonal forecast system (System 4). ECMWF Technical Memorandum 656

Rasmusson EM, Carpenter TH (1982) Variations in tropical sea surface temperature and surface wind fields associated with the Southern Oscillation/El Niño. Mon Weather Rev 110:354-384

Rayner NA, Parker DE, Horton EB, Folland CK, Alexander LV, Rowell DP, Kent EC, Kaplan A (2003) Global analyses of sea surface temperature, sea ice, and night marine air temperature since the late nineteenth century. J Geophys Res 108(D14):4407. https:// doi.org/10.1029/2002JD002670

Ren H-L, Jin F-F (2011) Niño indices for two types of ENSO. Geophys Res Lett 38:L04704. https://doi.org/10.1029/2010GL046031

Ren H-L, Jin F-F (2013) Recharge oscillator mechanisms in two types of ENSO. J Clim 26(17):6506-6523

Ren H-L, Jin F-F, Stuecker MF, Xie R (2013) ENSO regime change since the late 1970 s as manifested by two types of ENSO. J Meteor Soc Jpn 91(6):835-842

Ren H-L, Liu Y, Jin F-F, Yan Y-P, Liu X-W (2014) Application of the analogue-based correction of errors method in ENSO prediction. Atmos Oceanic Sci Lett 7(2):157-161. https://doi.org/10.3878/j. issn.1674-2834.13.0080

Ren H-L, Jin F-F, Tian B et al (2016) Distinct persistence barriers in two types of ENSO. Geophys Res Lett 43:10973-10979

Ren H-L, Jin F-F, Song L, Lu B, Tian B, Zuo J, Liu Y, Wu J, Zhao C, Nie Y, Zhang P, Ba J, Wu Y, Wan J, Yan Y, Zhou F (2017) Prediction of primary climate variability modes in Beijing Climate Center. J Meteorol Res 31(1):204-223. https://doi.org/10.1007/ s13351-017-6097-3

Saha S et al (2006) The NCEP climate forecast system. J Clim 19:3483-3517. https://doi.org/10.1175/JCLI3812.1

Saha $S$ et al (2010) The NCEP climate forecast system reanalysis. Bull Am Meteorol Soc 91:1015-1057. https://doi.org/10.1175/2010B AMS3001.1

Saha S et al (2014) The NCEP climate forecast system version 2. J Clim 27:2185-2208. https://doi.org/10.1175/JCLI-D-12-00823.1 
Scaife AA et al (2017a) Tropical rainfall, rossby waves and regional winter climate predictions. Quart J R Met Soc 143:1-11. https:// doi.org/10.1002/qj.2910

Scaife AA et al (2017b) Predictability of European winter 2015/16. Atmos Sci Let 18:38-44

Smith DM, Cusack S, Colman AW, Folland CK, Harris GR, Murphy JM (2007) Improved surface temperature prediction for the coming decade from a global climate model. Science 317:796-799. https://doi.org/10.1126/science. 1139540

Sung M-K, Kim B-M, An S-I (2014) Altered atmospheric responses to eastern Pacific and central Pacific El Niños over the North Atlantic region due to stratospheric interference. Clim Dyn 42(1-2): $159-170$

Toniazzo T, Scaife AA (2006) The influence of ENSO on winter North Atlantic climate. Geophys Res Lett 33:L24704. https://doi. org/10.1029/2006GL027881

Wang B, Lee J-Y et al (2009) Advance and prospectus of seasonal prediction: assessment of the APCC/CliPAS 14-model ensemble retrospective seasonal prediction (1980-2004). Clim Dyn 33:93-117

Weng H, Ashok K, Behera S, Rao AS, Yamagata T (2007) Impacts of recent El Niño Modoki on dry/wet conditions in the Pacific Rim during boreal summer. Clim Dyn 29:113-129. https://doi. org/10.1007/s00382-007-0234-0

Weng H, Behera SK, Yamagata T (2009) Anomalous winter climate conditions in the Pacific Rim during recent El Niño Modoki and El Niño events. Clim Dyn 32:663-674

Williams KD, Harris CM et al (2015) The Met Office global coupled model 2.0 (GC2) configuration. Geosci Model Dev 8:1509-1524

Wu TW et al (2010) The Beijing Climate Center atmospheric general circulation model: description and its performance for the presentday climate. Clim Dyn 34:123-147

Wu TW et al (2013) Global carbon budgets simulated by the Beijing Climate Center climate system model for the last century. J Geophys Res 118:4326-4347

Xiang B, Wang B, Li T (2013) A new paradigm for predominance of standing Central Pacific Warming after the late 1990s. Clim Dyn 41:327-340

Yang S, Jiang X (2014) Prediction of eastern and central Pacific ENSO events and their impacts on East Asian climate by the NCEP climate forecast system. J Clim 27:4451-4472. https://doi. org/10.1175/JCLI-D-13-00471.1

Yeh SW, Kug JS, Dewitte B, Kwon MH, Kirtman BP, Jin F-F (2009) El Niño in a changing climate. Nature 461:511-514
Yu J-Y, Kim ST (2010) Identification of central-Pacific and easternPacific types of ENSO in CMIP3 models. Geophys Res Lett 37:L15705. https://doi.org/10.1029/2010GL044082

Yu J-Y, Kao H-Y, Lee T et al (2011) Subsurface ocean temperature indices for Central-Pacific and Eastern-Pacific types of El Niño and La Niña. events. Theor Appl Climatol 103(3):337-344

Yuan Y, Yan H-M (2013) Different types of La Niña events and different responses of the tropical atmosphere. Chin Sci Bull 58:406415. https://doi.org/10.1007/s11434-012-5423-5

Yuan Y, Yang S (2012) Impacts of different types of El Niño on the East Asian climate: Focus on ENSO cycles. J Clim 25:7702-7722. https://doi.org/10.1175/JCLI-D-11-00576.1

Zebiak SE, Cane MA (1987) A model El Niño-Southern Oscillation. Mon Weather Rev 115:2262-2278

Zhang R, Sumi A, Kimoto M (1996) Impact of El Niño on the East Asia monsoon: a diagnostic study of the ' $86 / 87$ and ' $91 / 92$ events. J Meteorol Soc Jpn 74:49-62

Zhang W, Jin F-F, Li J, Ren H-L (2011) Contrasting impacts of twotype El Niño over the western north Pacific during boreal autumn. J Meteorol Soc Jpn 89(5):563-569

Zhang W, Jin F-F, Ren H-L, Li J, Zhao J-X (2012) Differences in teleconnection over the North Pacific and rainfall shift over the USA associated with two types of El Niño during boreal autumn. J Meteorol Soc Jpn 90(4):535-552

Zhang W, Wang L, Xiang B, Qi L, He J (2015) Impacts of two types of La Niña on the NAO during boreal winter. Clim Dyn 44:1351-1366

Zheng F, Zhu J, Zhang R-H et al (2006) Ensemble hindcasts of SST anomalies in the tropical Pacific using an intermediate coupled model. Geophys Res Lett 33:L19604

Zhu J, Huang B, Marx L, Kinter JL III, Balmaseda MA, Zhang R-H, $\mathrm{Hu}$ Z-Z (2012) Ensemble ENSO hindcasts initialized from multiple ocean analyses. Geophys Res Lett 39:L09602. https://doi. org/10.1029/2012GL051503

Zhu J, Huang B, Cash B, Kinter JL, Manganello J, Barimalala R, Altshuler E, Vitart F, Molteni F, Towers P (2015) ENSO prediction in project minerva: sensitivity to atmospheric horizontal resolution and ensemble size. J Clim 28:2080-2095. https://doi.org/10.1175/ JCLI-D-14-00302.1

Zhu J, Kumar A, Wang W, Hu Z-Z, Huang B, Balmaseda MA (2017) Importance of convective parameterization in ENSO predictions. Geophys Res Lett 44(12):6334-6342. https://doi. org/10.1002/2017GL073669 